Rivera-Hernández Frances (Orcid ID: 0000-0003-1401-2259)

Sumner Dawn, Y (Orcid ID: 0000-0002-7343-2061)

Mangold Nicolas (Orcid ID: 0000-0002-0022-0631)

Banham Steven (Orcid ID: 0000-0003-1206-1639)

Edgett Kenneth, S. (Orcid ID: 0000-0001-7197-5751)

Nachon Marion (Orcid ID: 0000-0003-0417-7076)

Newsom Horton E., E (Orcid ID: 0000-0002-4358-8161)

Stein Nathan (Orcid ID: 0000-0003-3385-9957)

Wiens Roger, C. (Orcid ID: 0000-0002-3409-7344)

\title{
Grain Size Variations in the Murray Formation: Stratigraphic Evidence for Changing Depositional Environments in Gale Crater, Mars
}

Frances Rivera-Hernández ${ }^{1,2}$, Dawn Y. Sumner ${ }^{2}$, Nicolas Mangold ${ }^{3}$, Steven G. Banham ${ }^{4}$, Kenneth S. Edgett ${ }^{5}$, Christopher M. Fedo ${ }^{6}$, Sanjeev Gupta ${ }^{4}$, Samantha Gwizd ${ }^{6}$, Ezat Heydari ${ }^{7}$, Sylvestre Maurice ${ }^{8}$, Marion Nachon ${ }^{2,9}$, Horton Newsom ${ }^{10}$, Juergen Schieber ${ }^{11,}$ Katie StackMorgan ${ }^{12}$, Nathan Stein ${ }^{13}$, Roger C. Wiens ${ }^{14}$

${ }^{1}$ Department of Earth Sciences, Dartmouth College, Hanover, NH, USA

${ }^{2}$ Earth and Planetary Sciences Department, University of California, Davis, CA, USA

${ }^{3}$ Laboratoire de Planétologie et Géophysique de Nantes, Université de Nantes, Nantes,

France

${ }^{4}$ Imperial College, London, U.K.

${ }^{5}$ Malin Space Science Systems, San Diego, CA, USA

${ }^{6}$ University of Tennessee in Knoxville, Knoxville, TN, USA

${ }^{7}$ Jackson State University, Jackson, MS, USA

${ }^{8}$ IRAP, Université de Toulouse, CNRS, UPS, CNES, Toulouse, France

${ }^{9}$ Texas A\&M, College Station, TX, USA

${ }^{10}$ University of New Mexico, Albuquerque, NM, USA

${ }^{11}$ Indiana University, Bloomington, IN, USA

12 Jet Propulsion Laboratory, California Institute of Technology, Pasadena, CA, USA

${ }^{13}$ California Institute of Technology, Pasadena, CA, USA

${ }^{14}$ Los Alamos National Laboratory, Los Alamos, NM, USA

Corresponding author: Frances Rivera-Hernández (Frances.Rivera-

Hernandez@Dartmouth.edu)

\section{Key Points:}

- A detailed record of inferred rock grain size was produced for the Murray formation using ChemCam laser induced breakdown spectroscopy data.

This article has been accepted for publication and undergone full peer review but has not been through the copyediting, typesetting, pagination and proofreading process which may lead to differences between this version and the Version of Record. Please cite this article as doi: 10.1029/2019JE006230 
- Inferred grain sizes in the Murray formation include mudstones and sandstones, with mudstones being the dominant lithology.

- Grain size variations suggest changing environments and sustained liquid water in Gale crater for tens of thousands to millions of years.

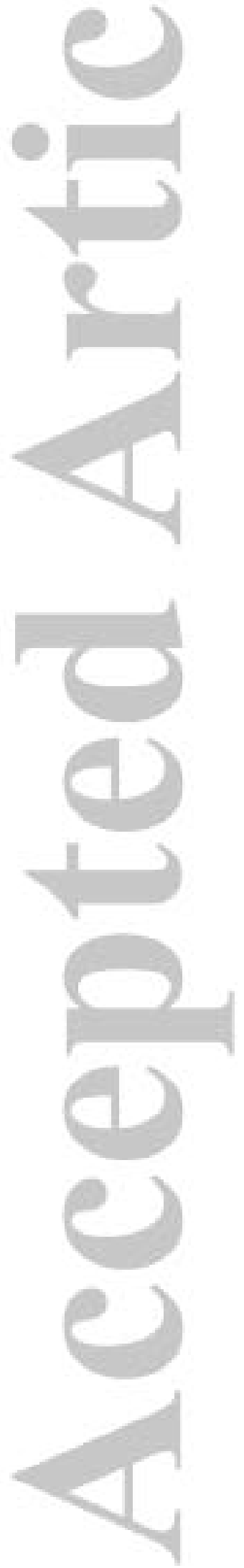




\section{- Abstract}

The lowermost exposure of the Murray formation in Gale crater, Mars, was interpreted as sediment deposited in an ancient lake based on data collected by the Curiosity rover.

Constraining the stratigraphic extent and duration of this environment has important implications for the paleohydrology of Gale. Insights into early martian environments and paleo-fluid flow velocity can be obtained from grain size in rocks. Visual inspection of grain size is not always available for rocks investigated at field sites on Mars due to limited image coverage. But grain sizes can also be estimated from the Gini Index Mean Score (GIMS), a grain-size proxy that uses point-to-point chemical variations in ChemCam Laser Induced Breakdown Spectroscopy (LIBS) data. New GIMS results indicate that the Murray formation is dominated by mudstones with grains smaller than the spatial resolution of all rover cameras. Intervals of fine to coarse sandstone also are present, some of which are verified using observations of grain size and sedimentary structures in associated images. Overall, results demonstrate that most of the Murray consists of mudstone, suggesting settling of grains from suspension in low energy depositional environments such as lakes. Some of the mudstones contain desiccation cracks indicating periods of drying with a lowering of lake water level. However, beds and lenses of cross-bedded sandstones are common at specific intervals, suggesting episodes of fluvial and possibly eolian deposition. The persistence of lacustrine deposits interspersed with fluvial deposits suggests that liquid water was sustained on the martian surface for tens of thousands to millions of years.

\section{Plain Language Summary}

The lowest exposed rocks of the Murray formation in Gale crater, Mars are interpreted as ancient lake deposits based on Curiosity rover data. However, the duration and temporal variability of this ancient lake is still an open question. Here we characterize the vertical distribution of deposits within the entire Murray formation using new grain size information. 
Characterizing grain size in rocks provides information about the speed of past fluid flows, which is crucial for interpreting depositional environments. However, measuring grain size in images is rarely possible for martian rocks. Thus, we estimate grain sizes with the Gini Index Mean Score (GIMS), a grain-size proxy that uses ChemCam Laser Induced Breakdown Spectroscopy data. GIMS results indicate that the Murray formation is dominated by rocks with mud-sized grains (i.e., mudstones), suggesting mud-sized grain settled in a low energy lake environment. Mud cracks occur in some of the mudstones, indicating drying periods in a lake. Rocks with sand-sized grains (i.e., sandstones) and cross bedding occur at specific intervals, suggesting episodes with stream channels and wind-blown sand dunes. The dominance of lake deposits interspersed with stream deposits suggests that liquid water was present in Gale crater for tens of thousands to millions of years.

\section{Introduction}

The Murray formation includes the lowermost exposed strata of Mt. Sharp (formally known Aeolis Mons), Gale crater's 5-km-high central mountain (Figure 1). The Mars Science Laboratory (MSL) team has been using the Curiosity rover tools and instruments to reconstruct the record of ancient habitable environments in Gale crater (e.g., Grotzinger et al., 2012). The lowermost exposure of the Murray formation at the Pahrump Hills site was extensively studied and consists of interstratified laminated mudstones and sandstones, interpreted as having accumulated in an ancient lacustrine environment (Grotzinger et al., 2015; Rivera-Hernández et al., 2019; Stack et al., 2019). Lacustrine facies are of particular interest to the MSL mission because they provide evidence for sustained liquid water, and lake muds commonly preserve biosignatures on Earth (Farmer and DesMarais, 1999;

Summons et al., 2011). The duration of the lake or episodic lakes recorded by the Murray formation can be reconstructed from the distribution of lacustrine facies, which are 
interspersed with facies deposited in other environments. The stratigraphic distribution of these facies records the duration and diversity of depositional environments and can provide insights into the habitability of early Mars.

Grain size is an important parameter used to characterize sedimentary facies and reconstruct past depositional environments because grain size relates to transport processes, specifically paleo-fluid flow velocity. For example, rocks that are laminated and dominated by mud-sized grains (i.e., mudstones) accumulated in environments with very low flow speeds such as lakes, whereas cross-bedded sandstones required higher flow speeds and accumulated in environments like rivers and beaches. Determining the grain size in sedimentary rocks on Mars is challenging due to a paucity of high spatial resolution images (Yingst et al., 2016). Whether

grains can be resolved in an image from Mars depends on a variety of factors, such as camera characteristics, the distance of the camera from the rock, illumination, grain color contrast, and eolian dust cover. In addition, the distance between localities in which high spatial resolution images are acquired (generally tens of meters) are often larger than the scale of vertical facies changes. Because of these limitations, a composition-based grain-size proxy was developed. The Gini Index Mean Score (GIMS) uses point-to-point chemical variations in ChemCam Laser Induced Breakdown Spectroscopy (LIBS) data to provide grain size information (Rivera-Hernández et al., 2019). At every rover locality, the ChemCam LIBS instrument normally targets multiple rocks, each with multiple observation points, providing a rich source of data that complements image-based interpretations of grain sizes.

Here, we apply the GIMS technique to the abundance of ChemCam LIBS data to help characterize the sedimentary facies of the Murray formation. Results from this study add to grain size information acquired using image data (Fedo et al., 2018; Stack et al., 2019;

Rivera-Hernández et al., 2019). These refined grain size constraints provide new insights into 
the details of the depositional environments preserved in the Murray formation, and thus enhance our understanding of the habitability of early Mars.

\section{Methods}

The GIMS (Rivera-Hernández et al., 2019) was applied to ChemCam LIBS data to estimate grain sizes in sedimentary rocks of the Murray formation. The ChemCam instrument suite includes the LIBS and the Remote Micro-Imager (RMI) that collects co-located context images (Maurice et al., 2012; Wiens et al., 2012). ChemCam uses a pulsed laser to ablate $\sim 0.5 \mathrm{~mm}$ diameter spots, commonly in lines of 5 to 10 points or matrices of $3 \times 3$ points, on rocks 2 to $7 \mathrm{~m}$ away from the instrument (Maurice et al., 2012; Wiens et al., 2012). The points are usually spaced by $2 \mathrm{mrad}$, which represents an analysis point every $6 \mathrm{~mm}$ for a rock target at $3 \mathrm{~m}$ distance. The light from the plasma created by each laser pulse is passed through three spectrometers to acquire atomic emission spectra (Maurice et al., 2012; Wiens et al., 2012). By comparing the ChemCam LIBS spectra to those of standards, including onboard calibration targets, the weight percent of eight major-element oxides $\left(\mathrm{SiO}_{2}, \mathrm{TiO}_{2}\right.$, $\mathrm{Al}_{2} \mathrm{O}_{3}, \mathrm{FeO}_{\mathrm{T}}, \mathrm{MgO}, \mathrm{CaO}, \mathrm{Na}_{2} \mathrm{O}$, and, $\mathrm{K}_{2} \mathrm{O}$ ) are derived by multivariate analysis (Clegg et al., 2009, 2017; Wiens et al., 2013). FeO ${ }_{\mathrm{T}}$ refers to total iron, including both ferric and ferrous iron, as oxidation state cannot be determined from LIBS spectra (Clegg et al., 2009, 2017). If a rock is composed entirely of the major-element oxides, then the total weight percent sum of oxides equals $100 \%$. When the major-element oxide total is less than $100 \%$, there is at least one missing component in the multivariate model, assuming that all of the major-element oxide percentages are accurate. Missing components in the multivariate model are commonly sulfate minerals (Nachon et al., 2014, 2017) or other salts.

The width of each point vaporized by the ChemCam laser ranges between $\sim 0.4-0.6$ $\mathrm{mm}$ in diameter (medium to coarse sand in size). Rocks with grains smaller than the laser 
spot size produce bulk rock compositions at all LIBS points and low point-to-point chemical variability (Anderson et al., 2011; McCanta et al., 2013, 2017; Sivakumar et al., 2014; Mangold et al., 2017; Rivera-Hernández et al., 2019). In contrast, rocks with grains of variable composition that are larger than approximately half the laser spot diameter often have high point-to-point chemical variability due to the presence of different grains at each analysis point (Rivera-Hernández et al., 2019). If a rock has grains much larger than the distance between the LIBS points (typically $\sim 6 \mathrm{~mm}$; pebble or larger), then the laser may hit the same grain more than once, reducing chemical variability (Rivera-Hernández et al., 2019). Thus, for sedimentary rocks with variable grain compositions and grains smaller than pebble in size, grain size can be inferred by quantifying point-to-point variability in the LIBS data (Sivakumar et al., 2014; Mangold et al., 2017; Rivera-Hernández et al., 2019). Typically for the ChemCam LIBS, the variation in composition between repeated measurements of the same target (i.e., precision) is generally much smaller than the accuracy, which is the uncertainty in the absolute composition.

Compositional variabilities were quantified and used as a proxy for grain size by applying the GIMS (Rivera-Hernández et al., 2019). The GIMS uses a statistical measurement called the Gini index $(G)$, which has values that are non-dimensional and vary from 0 to 1 . When applied to grain size, a $\mathrm{G}=0$ indicates that a rock has grains much smaller than the laser spot size (mud) or are of a uniform composition, and if $\mathrm{G}=1$, then the laser hit distinct compositions at each LIBS point, and the grain size is likely larger than the spot size (Mangold et al., 2017; Rivera-Hernández et al., 2019). The output of the GIMS is a mean Gini index, GMEAN, and a standard deviation, STDr, for each rock target in a sample suite. For this study, GMEAN is calculated using the Gini index of each normalized major-element oxide except $\mathrm{TiO}_{2}$ (Rivera-Hernández et al., 2019) and rounded to two decimal places. STDr is 
calculated by propagating the standard deviation of each LIBS point and major-element oxide through the GIMS analysis using an iterated bootstrap with 1000 iterations (RiveraHernández et al., 2019).

The GIMS is a robust technique to estimate grain size differences in rocks with compositionally heterogeneous grains finer than medium sand in size (approximate LIBS spot size). In general, $\mathrm{G}_{\mathrm{MEAN}}$ increases with increasing grain size for rocks with mud to medium sized grains (Rivera-Hernández et al., 2019). However, rocks composed of medium sand to pebble-sized grains can produce similar $\mathrm{G}_{\mathrm{MEAN}}$ values because the grains are larger than the LIBS spot size and smaller than the LIBS spacing ( $\sim \mathrm{mm}$ ) (Rivera-Hernández et al., 2019).

For each study, the GIMS first has to be applied to rocks of known grain size to calibrate the relationship between grain size and major-oxide variability (Rivera-Hernández et al., 2019). This calibration step is essential because rocks of uniform grain compositions will not produce chemical variability, regardless of grain size. In contrast, rocks containing compositionally diverse grains produce useful variability, but the variability depends critically on the ranges of grain compositions (Rivera-Hernández et al., 2019). For this study, grain sizes of rock standards (i.e., rocks with resolvable grains) were measured in images acquired by the Mars Hand Lens Imager (MAHLI) (Edgett et al., 2012, 2015), and the ChemCam RMI (Le Mouélic et al., 2015). MAHLI can resolve coarse silt at a distances of $\sim 2$ to $4 \mathrm{~cm}$, and the RMI can resolve fine to medium sand at distances of 2 to $3 \mathrm{~m}$. Images acquired by the Mast Cameras (Mastcams) (Malin et al., 2017; Bell et al., 2017) were used to provide context at the outcrop scale for the grain size analyses. MAHLI and the Mastcams provide color images, whereas RMI images are panchromatic. Most ChemCam targets are also imaged by the Mastcams and some are also imaged by MAHLI. RMI images are particularly useful for characterizing grain sizes for the GIMS analyses because they 
specifically show the regions targeted by the ChemCam LIBS at a spatial resolution in which both the ablated laser spots and grains may be resolved (Rivera-Hernández et al., 2019). The rock standards that were chosen to calibrate the GIMS have several resolvable grains near the LIBS laser pits in MAHLI and/or RMI images (see Section 4).

Determining grain size from rover images has its own limitations, as factors such as dust cover, spatial resolution, and grain contrast can obscure textures and individual grains. Despite these challenges, the MAHLI and RMI images are the best visual record of grain size available from Mars, and thus are used as the standard to which GIMS grain size estimates are compared.

Three main criteria are used to identify grains in rocks from images (modified from Rivera-Hernández et al. (2019)): grains have to 1) be embedded in the rock, 2) ideally exhibit positive relief, and 3) be discrete to distinguish them from scratches made by the metallic bristles of the dust removal tool on the rover (Davis et al., 2012). The longest axis of each visible grain surface was measured. Grain sizes were classified using the Wentworth scale (Wentworth, 1922), in which very fine sand $=62.5-125 \mu \mathrm{m}$, fine sand $=125-250 \mu \mathrm{m}$, medium sand $=0.25-0.50 \mathrm{~mm}$, coarse sand $=0.50-1.00 \mathrm{~mm}$, very coarse sand $=1.00-2.00 \mathrm{~mm}$, and very fine gravel (granule)=2.00-4.00 mm. Clay- and silt-sizes were grouped together as mud (62.5 $\mu \mathrm{m}$ and smaller), in which coarse silt is 20.0-62.5 $\mu \mathrm{m}$. A mud grain size was inferred for targets that did not have resolvable grains in MAHLI images $(<62.5 \mu \mathrm{m}$, coarse silt). Due to limited resolution of the images and to eolian dust coatings on the rocks, the median grain size of a rock is likely smaller than the finest resolvable grain in an image (Schieber et al., 2018).

The accurate application of the GIMS depends on excluding targets where heterogeneities are introduced by factors other than grain size. Heterogeneities in composition can be caused by contamination from loose sand and dust, diagenetic features 
(e.g., veins, concretions, and nodules), and intergranular cements. These effects were minimized by filtering potential rock targets as outlined in Rivera-Hernández et al. (2019). RMI images were examined to identify where the LIBS laser ablated every point on each rock. Points that sampled visually resolvable diagenetic features, loose sediment, cracks, or sharp edges were excluded from the GIMS analysis. Points with $<88 \%$ major-element oxide totals were also excluded from the analysis, because the studied rocks are siliciclastic. Thus, low oxide totals suggest the presence of diagenetic phases such as sulfates and other salts in the form of cement, concretions, nodules or veins (e.g., Jackson, 2016; Nellessen et al., 2018). Rock targets with abundant diagenetic features in the RMI scene were excluded from the GIMS analysis, even if the laser did not hit any resolvable features. After the filtering process, only rock targets with more than five points were used for the GIMS analysis, as that is the minimum number of points necessary to obtain a statistically significant Gini index result (Mangold et al., 2017; Rivera-Hernández et al., 2019).

\section{Geologic setting}

\subsection{The Curiosity rover in Gale crater}

The Curiosity rover landed in Gale crater on 6 August 2012 (Fig. 1). Gale is located at $137.7^{\circ} \mathrm{E}, 5.44^{\circ} \mathrm{S}$ and lies along the crustal dichotomy boundary between the planet's smooth northern lowlands and the cratered southern highlands. The crater is $\sim 154 \mathrm{~km}$ in diameter and Mt. Sharp extends $\sim 5 \mathrm{~km}$ upward from the crater floor. Based on crater count analysis, Gale is interpreted to have formed at the Noachian-Hesperian transition $(3.7 \pm 0.1 \mathrm{Ga})$ (Thomson et al., 2011; Le Deit et al., 2013). Further crater count studies suggest that the $\geq 5 \mathrm{~km}$ of Mt. Sharp stratigraphy, and strata below the present floor, were deposited from the Noachian through the early Hesperian (Thomson et al., 2011; Grant et al., 2014; Palucis et al., 2014; 
Grotzinger et al., 2015). The exposed strata record the environmental history of Gale crater.

Abundant data were collected from exposures of the Murray formation, which is the lowermost unit exposed on the north side of Mt. Sharp (Fig. 1b). On Sol 750, Curiosity reached the lowermost exposed strata of the Murray formation at Pahrump Hills (Fig. 1) (Grotzinger et al., 2015). The sedimentary facies at Pahrump Hills were interpreted as fluviallacustrine, with mudstones representing lacustrine deposition and sandstones representing fluvial-deltaic deposition (Grotzinger et al., 2015). After leaving Pahrump Hills, the rover spent >1000 sols traversing up-section through the Murray formation (e.g., Fedo et al., 2018).

Parts of the Murray formation are heterolithic (interbedded sand and mud deposits) (e.g., Fedo et al., 2018), demonstrating the presence of important lithofacies changes along the traverse. Typically grain size changes in the heterolithic regions occur at scales smaller than the distance between areas imaged by the MAHLI camera. The presence of sand in these cases has been inferred indirectly by observing sedimentary structures associated with bedload transport (e.g., cross stratification) and comparing to previously-encountered outcrops where grain size was directly determined using MAHLI images.

3.2 Sedimentology and stratigraphy of the Murray formation

The Murray formation. The exposed section of the Murray formation explored by Curiosity is $\sim 300 \mathrm{~m}$ in thickness, and it extends from, at least, Pahrump Hills southward through the top of the hematite-bearing Vera Rubin ridge (Fig. 1b) (Fraeman et al. 2013, 2016). The

mean dip of the Murray formation below the VRR is approximately horizontal, which allows elevation, referenced to the zero elevation Mars datum (Smith et al., 2001), to be used as an approximation for stratigraphic position (Grotzinger et al., 2015). Curiosity was used to 
investigate numerous outcrops within the Murray formation, and these have been subdivided by the MSL science team into seven stratigraphic members, informally called (in ascending stratigraphic order): Pahrump Hills, Hartmann's Valley, Karasburg, Sutton Island, Blunts Point, Pettegrove Point, and Jura (Fig. 2a). These stratigraphic members contain named localities, and these are informally called (in ascending stratigraphic order): Pahrump Hills, Marias Pass, Bridger Basin, Hartmann's Valley, Murray Buttes, Sebina, Old Soaker, Ireson Hill, Paradise Hill, Newport Ledge, Heron Island, Blunts Point, Pettegrove Point, Jura, and Lake Orcadie (Fig. 2a). The Pettegrove Point, Jura, and Lake Orcadie localities are exposed in the Vera Rubin ridge, and are not further discussed in this manuscript. The named localities are used to place surrounding rocks intro stratigraphic context. From the upper Pahrump Hills member to the Karasburg member, Murray formation strata are unconformably overlain by the eolian sandstones of the Stimson formation (Watkins et al., 2016; Banham et al., 2018). Rocks from the Stimson formation are also not discussed in this manuscript.

Overall, the rocks of the Murray formation can be grouped into three major sedimentary facies. Facies 1, observed at Pahrump Hills and Marias Pass, consists of finely laminated gray-reddish colored, fine-grained rocks with sandstone interbeds (Grotzinger et al., 2015; Stack et al., 2019; Rivera-Hernandez et al., 2019). Facies 2, seen at Hartmann's Valley, exhibits meter-scale trough cross bedding with steep foresets (Fedo et al., 2018; Gwizd et al., 2018, 2019). Facies 3, observed from Sebina to the Blunts Point outcrops, is heterolithic and consists of dark red, finely laminated mudstone, centimeter-scale ripple-cross-laminated sandstone, and decimeter-scale cross-stratified sandstone (Fedo et al., 2018). There are variations in the heterolithic facies (Fig. 2). For example, at Old Soaker, Facies 3 also contains distinctive, small-scale polygonal fractures interpreted as desiccation cracks (Stein et al., 2018). The 
association of Facies 1-3 in the Murray formation is consistent with progradation of sediments from the crater margin into a lake that occupied part of the interior of Gale crater, possibly intermittently (Grotzinger et al., 2015; Fedo et al., 2018).

To date, the best-studied locality in the Murray formation is the Pahrump Hills outcrop, where the rover spent 120 sols (6 and a half months). During this time the outcrop was co-investigated using all instruments on the rover during three successive traverses (e.g. Minitti et al., 2019; Stack et al., 2019). The rocks from Pahrump Hills are discussed in more detail below as they provide stratigraphic context for the rest of the Murray formation.

\section{Pahrump Hills Locality: The Pahrump Hills member contains the lowest exposed} strata of the Murray formation (Fig. 2a) (Grotzinger et al., 2015). The Pahrump Hills locality, the lowermost section of the Pahrump Hills member, was investigated at nine exposures, in ascending stratigraphic order, these are informally called: Shoemaker, Confidence Hills, Pink Cliffs, Book Cliffs, Alexander Hills, Chinle, Telegraph Peak, Whale Rock, and Salsberry Peak (Fig. 2b). The Pahrump Hills locality is $\sim 14 \mathrm{~m}$ thick and is dominated by laminated mudstones and siltstones with sandy intervals including the cross-bedded sandstones of the Whale Rock outcrop (Grotzinger et al., 2015; Stack et al., 2019; Rivera-Hernández et al., 2019). The association of facies at Pahrump Hills is consistent with a coarsening-upward trend and has been interpreted as recording a prograding fluvial-lacustrine depositional system, with the mudstones representing lacustrine environments and sandstones recording plunging river plume deposits on a delta slope (Grotzinger et al., 2015; Stack et al., 2019).

3.3 Composition and diagenetic history of the Murray formation

The majority of the rocks in the Murray formation have bulk compositions lower in $\mathrm{CaO}$ and $\mathrm{MgO}$ and higher in $\mathrm{SiO}_{2}, \mathrm{Al}_{2} \mathrm{O}_{3}$, and $\mathrm{K}_{2} \mathrm{O}$ compared to martian average crust which 
is basaltic (see Table S2) (Grotzinger et al., 2015; Rampe et al., 2017; Bedford et al., 2019). The Murray formation contains a diverse suite of grain compositions, including pyroxenes, feldspars, olivines, other mafic minerals, lithic fragments, and amorphous material (Rampe et al., 2017). Up to $28 \%$ clay minerals are also present, which-combined with the depletion of $\mathrm{CaO}$ and $\mathrm{MgO}-$ suggests that significant alteration of the sediment occurred during transport or open system diagenesis (Bristow et al., 2018; Mangold et al., 2019). However, the persistence of mafic minerals implies incomplete weathering of the sediment (e.g., Bedford et al., 2019) and sufficient chemical variability to apply the GIMS technique.

The Murray formation contains diverse diagenetic features that are associated with specific oxides, such as $\mathrm{CaO}, \mathrm{FeO}$, and $\mathrm{MgO}$, which have been described in detail for the Pahrump Hills member (Nachon et al., 2017; L'Haridon et al., 2018; Kronyak et al., 2019; Sun et al., 2019). Mineral-filled fractures (i.e., Ca-sulfate-bearing veins) are the most pervasive and these have different enrichments and surface characteristics, which include Feand Mg-rich white veins, Mg-rich gray veins, and Fe-, K-, and F-rich dark-toned veins (Nachon et al., 2017; L'Haridon et al., 2018; Kronyak et al., 2019). Concretions and nodules enriched in $\mathrm{MgO}$ are also common in the Murray formation (Nachon et al., 2017; Sun et al., 2019). Other observed diagenetic features include local dendritic aggregates, enhanced relief features with various geometries, and dark raised ridges with local $\mathrm{Mg}$-sulfates and jarosite (Nachon et al., 2017). The lower outcrops of the Pahrump Hills member also preserve evidence for diagenetic mineral precipitation, including likely in situ precipitation of lenticular features interpreted as crystal pseudomorphs (Kah et al., 2018), preferential cementation of specific laminae, precipitation of late diagenetic crystal clusters, and secondary overprinting of previously-formed crystals (Yingst et al., 2017). Rocks with observable diagenetic features in RMI images were excluded from the GIMS analysis because diagenesis can obscure the relationship between chemical variability and grain size. 
At Marias Pass and Bridger Basin, the Murray formation is enriched in silica (>60 wt $\% \mathrm{SiO}_{2}$ ) with values up to $80 \mathrm{wt} \%$ (Morris et al., 2016; Frydenvang et al., 2017; Yen et al., 2017). Various phases of silica were identified by the CheMin x-ray diffraction instrument, including tridymite, which was interpreted as a detrital component of silicic volcanic rocks (Morris et al., 2016). Enrichments in silica were also observed in light-toned halos associated with fractures cross-cutting the Murray and Stimson formations, suggesting post-depositional circulation of a Si-rich fluid (Frydenvang et al., 2017). Rocks with high $\mathrm{SiO}_{2}(>70$ wt \%) were excluded in the GIMS analysis due to their inferred diagenetic alteration.

\section{GIMS analysis of the Murray formation}

ChemCam sampled 1119 unique targets from Sol 750 to 1804, including Murray and Stimson formation bedrock, drill holes and tailings, float rocks, and unconsolidated sediment such as sand and pebble clasts. Of these, 209 ChemCam LIBS rock targets in the Murray formation passed the filtering process and were used in the GIMS analysis (Table S2). Out of those, 22 rock targets with grain size determined through visual inspection of MAHLI or RMI images were chosen to calibrate $\mathrm{G}_{\text {MEAN }}$ to grain size as standards (Fig. 3, Table S1). To calibrate the GIMS, grain size results from Rivera-Hernandez et al. (2019) and Stack et al. (2019) were used and supplemented with those for all MAHLI and RMI rock targets with resolvable silt- to fine sand-sized grains. For rock targets with grains coarser than fine sand, only those rocks with several resolvable grains near or at the LIBS observation points were selected as calibration standards. The names of the ChemCam and MAHLI targets, were chosen by the MSL science team and are archived in the Planetary Data System (PDS; see Text S1).

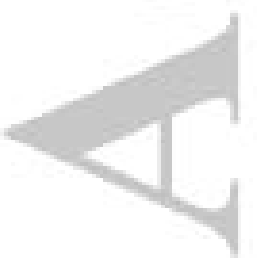




\subsection{Calibration of the GIMS to grain size}

The 22 rock standards range in lithology from mud to very coarse sand and represent multiple stratigraphic intervals (Fig. 3, Table S1). The magnitude of $\mathrm{G}_{\mathrm{MEAN}}$ increased consistently with grain size between mud and medium sand (Fig. 3). The standards consisting of mud sized grains have $\mathrm{G}_{\mathrm{MEAN}}$ ranging from $0.04 \pm 0.01$ to $0.07 \pm 0.00$, whereas standards composed of medium to coarse sand have $\mathrm{G}_{\text {MEAN }}$ ranging from $0.17 \pm 0.01$ to $0.29 \pm 0.01$.

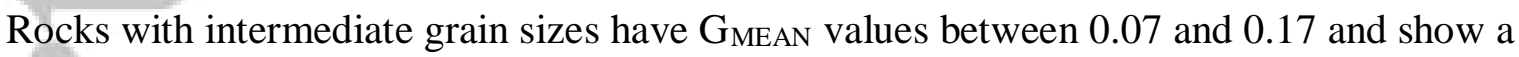
strong correlation between grain size and $\mathrm{G}_{\text {MEAN }}$ (Fig. 3). However, standards with grain sizes of medium sand and coarser, especially those that are poorly sorted, do not show a correlation between grain size and GMEAN, although they all have $\mathrm{G}_{\mathrm{MEAN}}>0.17$ (Fig. 3).

These results demonstrate that $\mathrm{G}_{\text {MEAN }}$ can be used to estimate grain sizes within the mudstone to medium sandstone range. The absence of a correlation between $\mathrm{G}_{\mathrm{MEAN}}$ and the grain size of medium to very coarse sandstones demonstrates that the technique is not sensitive to variations in these grain sizes for the rock compositions in the Murray formation. Thus, four different grain size regimes (GSR1-4) were defined: mud $\left(\mathrm{G}_{\mathrm{MEAN}}=0.00-0.07\right.$; GSR1), coarse silt to very fine sand ( $\mathrm{G}_{\text {MEAN }}=0.07-0.10$; GSR2), very fine to medium sand $\left(\mathrm{G}_{\mathrm{MEAN}}=0.11-0.16 ; \mathrm{GSR} 3\right)$, and medium to very coarse sand $\left(\mathrm{G}_{\mathrm{MEAN}}=0.17-0.29 ; \mathrm{GSR} 4\right)$. The upper and lower $\mathrm{G}_{\mathrm{MEAN}}$ bounds of the GSRs were defined by using the minimum and maximum $\mathrm{G}_{\text {MEAN }}$ of the rock

standards in each bin (Table 1). A value of 0.00 was used as the lower bound of GSR1 as that is the theoretical minimum for a homogenous rock (see Section 2). Rocks with $\mathrm{G}_{\mathrm{MEAN}}=0.07$ are exactly at GSR1 and GSR2 boundary and are reported as GSR1/GSR2. The boundaries of GSR3 are not as well constrained as the other bins because it has only three rock standards and only one rock had grain sizes characterized from MAHLI images (Conda; $\mathrm{G}_{\mathrm{MEAN}}=0.13$ ). The paucity of standards is due to the low representation of rocks determined to be composed 
of very fine to medium sand based on image analysis. All three GSR3 rock targets with good grain size estimates were used as standards; other targets thought to be in this size range showed poor sorting, lacked color contrast among grains, or were not imaged with high enough resolution (Table S3).

Overall, the calibration supports confident identification of rocks in GSR1 and GSR2, which represent grain sizes that can only rarely be determined from image data. GSR3 and GSR4 are less well resolved in terms of constraining specific sand grain sizes, but no mudstone or siltstone targets show GMEAN values in GSR3 or GSR4. Thus, the GIMS technique can be used to reliably distinguish among mudstones, siltstones to very fine sandstones, and coarser sandstones in the Murray formation.

\subsection{Grain size variations in the Murray formation}

The $\mathrm{G}_{\text {MEAN }}$ of all 209 rocks that passed screening in the Murray formation ranges from 0.01 to 0.32 (Table S3). Most rocks fall within GSR1 (129 rocks), with 55 rocks having $\mathrm{G}_{\text {MEAN }}$ lower than the GSR1 rocks standards $\left(\mathrm{G}_{\mathrm{MEAN}}<0.04\right.$, Table $\left.\mathrm{S} 3\right)$. An additional 16 rocks have a $\mathrm{GMEAN}_{\mathrm{ME}}=0.07$ and are transitional between GSR1 and GSR2, 23 are in GSR2, 22 are in GSR3, and 19 are in GSR4 (Fig. 4). Two rocks have GMEAN greater than GSR4 rock standards $\left(\mathrm{G}_{\mathrm{MEAN}}>0.29\right.$, Table $\left.\mathrm{S} 3\right)$. The mean, median, maximum, and minimum $\mathrm{G}_{\mathrm{MEAN}}$ values for each stratigraphic interval in the Murray formation together with their associated standard deviation errors are summarized in Table S4.

In addition to the rock standards, other Murray rocks have grain size estimates from images. The ChemCam LIBS targeted some of these rocks more than once (i.e., multiple rasters), providing an opportunity to compare the GIMS results to grain size estimates from images and investigate local scale grain size variations (Table S3). In some cases, when grains could not be resolved, other sedimentary textures (e.g., cross bedding) were used to 
compare to the GIMS analysis. In general, the GSR of these rocks is consistent with the constraints on grain sizes from images, as discussed below for specific localities.

The predominance of rocks in GSR1 $(61 \%)$ indicates that the Murray formation is dominated by mudstone, and all stratigraphic intervals contain rocks in GSR1. However, the range of $\mathrm{G}_{\text {MEAN }}$ values within any given stratigraphic interval varies along the rover traverse (Fig. 4; Table S3). The largest GSR variations occur at the transition between the Sutton Island and Blunts Point members, where the GSR range increases from GSR1-GSR2 at Paradise Hill to GSR1-GSR4 at Newport Ledge and then decreases to GSR1 at Blunts Point. The Blunts Point locality and its surrounding region is the sole interval with only GSR1 rocks. Four key outcrops in the Murray formation highlight the stratigraphic diversity of grain size. These are: Marias Pass, Old Soaker, Newport Ledge, and Heron Island. Select GIMS results from these intervals are presented below in ascending stratigraphic order.

At Marias Pass, three rock targets illustrate the effects of poor and variable sorting. Here, the Missoula outcrop includes Stimson formation sandstones, an erosional unconformity, and underlying Pahrump Hills member (Murray formation) rocks (Fig. 5a; at -4446 m; Newsom et al., 2017). The Murray formation at Missoula contains the ChemCam target named Wallace. Wallace falls within GSR4, and based on image analysis, it has fine to coarse sand-sized grains disseminated in a mud matrix. Because the large grains produce chemical heterogeneities in the analysis, this grain size range is consistent with the GSR4 classification (Fig. 5b). About a meter away and slightly higher stratigraphically, ChemCam analyzed the rock standards Stenerson and Wapiti, which are located several millimeters from each other (Fig. 5c). Stenerson and Wapiti fell within GSR3, and associated RMI images show fine to medium sand size grains in an unresolvable matrix (Fig. 5c). The GSR3 classification for Stenerson, and Wapiti versus the GSR4 classification for Wallace is consistent with resolvable grain size variations between the targets. The grain size range 
classification also demonstrates that if a rock is poorly sorted and the grains are coarsely skewed, the LIBS laser may preferentially hit the larger grains, resulting in a $\mathrm{G}_{\text {MEAN }}$ that may not represent the mean grain size of the rock.

The rock called Old Soaker, approximately $100 \mathrm{~m}$ stratigraphically higher than Marias Pass, demonstrates the consistency of the GIMS results between analyses taken on the same stratigraphic horizon of a rock. Old Soaker contains a horizontal surface covered with diagenetic veins and small-scale polygonal fractures interpreted by Stein et al. (2018) as desiccation cracks (Fig. 6a; at -4335 m). Multiple LIBS analyses were targeted millimeters to tens of millimeters away from each other on the host rock as well as the veins. LIBS analyses associated with veins were not used in the GIMS analysis. Four analyses of the polygonally cracked red layer of the Old Soaker rock fell within GSR1 (Somes_Sound, Schoodic_Peninsula, Northeast_Harbor, and Dix_Point; Table S3), whereas one is classified as GSR1/GSR2 (Beech_Mountain_ccam; Table S3). The consistency of the GSR1 designation between different analyses on the polygonally cracked red layer supports the presence of mud sized grains in this horizon. In contrast, the one analysis of the Old Soaker rock in GSR3 (South_Bubble; Table S3) is located in a different stratigraphic horizon, at the top of a grey bed underlying the cracked red layer (Fig. 6a). The GSR variability between the red and grey bed likely represents stratigraphic (i.e., vertical) grain size changes in the Old Soaker rock.

The region from the Newport Ledge (at $\sim-4286 \mathrm{~m}$ ) to the Heron Island (at $-4265 \mathrm{~m}$ ) localities contains rocks that yield GIMS results ranging from GSR2 to GSR4. At the region near Newport Ledge, two LIBS analyses were taken in lighter-toned and darker-toned red layers of the same bedrock, targets Waterfall_Bridge and Duck_Brook_Bridge. The targets are a couple tens of centimeters away from each other, laminated, and have granular textures. Duck_Brook_Bridge falls in GSR2 whereas Waterfall_Bridge falls in GSR3 (Fig. 6b). 
Surrounding rocks also have lighter-toned and darker-toned layers suggesting that the color differences are likely not due to dust cover. Instead, the color variability between the layers may reflect grain size and/or diagenetic differences, either of which could have led to different GSR classifications. However, Waterfall_Bridge is a couple of millimeters away and approximately in the same stratigraphic layer as the MAHLI target Cliffside_Bridge, which has fine to medium sand-sized grains, consistent with the GSR3 result. In contrast, Duck_Brook_Bridge (GSR2) is from a stratigraphically higher layer, and grains could not be confidently resolved on the target from MAHLI images due to loose material from the use of the dust removal tool.

Also within the Newport Ledge region, but seven meters stratigraphically higher (at 4279 m elevation), outcrops are consistently cross stratified (Fig. 7a). The Mount_Gilboa target on these sandstones fell within GSR4. Mount_Gilboa does not have resolvable grains,

but the observed cross stratification is consistent with an abundance of sand sized grains (Fig. 7a). The presence of sand in the Murray formation continues higher stratigraphically into the Heron Island interval. The Heron_Island (at $-4265 \mathrm{~m}$ ) target is also in GSR4 although it shows fine to medium sand grains in MAHLI images. Nearby rocks contain trough cross bedding, indicating an abundance of sandstones in this area (Fig. 7b).

\section{Comparison between GIMS results and grain size from images}

Overall, grain size estimates from images for rocks that are not GSR standards support the GSR classifications and GIMS results for the rest of the Murray formation. GSR1 rocks could not be confirmed using image data because all rocks with coarse silt sized grains in images (upper limit of GSR1), where used as standards and grains smaller than coarse silt are below the minimum resolution of all rover images. However, none of the GSR1 rocks have resolvable sedimentary structures associated with bedload transport (e.g., cross 
stratification), instead they are commonly planar laminated (Fig. 7c). In addition to planar lamination, small-scale polygonal fractures interpreted as desiccation cracks that formed in contracting mud occur on a subset of rocks in the Old Soaker region (Fig. 6a; at -4335 m;

Stein et al., 2018), helping support the GSR1 classification. Coarse silt to very fine sand sized grains are at the boundary of spatial resolution for all of the cameras on the rover, making it difficult to confidently resolve the presence of grains in GSR2 rocks. Thus, none of the GSR2 rocks were confirmed using images (not including the GSR2 rock standards). In contrast, very fine to medium sand sized grains were resolved in six GSR3 rocks and medium to coarse sized sand grains were resolved in five GSR4 rocks. In addition, several GSR3 and GSR4 rocks have granular textures and/or are cross stratified, suggesting the presence of sand (e.g., Fig. 7a). Only seven rocks in GSR4 could not be verified as sandstones from associated images. The inability to resolve grains in images of some GSR4 targets might be due to low color contrast among grains given that medium and coarser sand with high color contrast should have been visible in both MAHLI and RMI images. Alternatively, the high GMEAN values might be due to heterogeneous diagenetic phases that were not identified during the screening process. Thus, these seven samples show significant chemical heterogeneity that could be due to either grain size or alteration.

\section{Depositional environments in the Murray formation}

Grain size transitions from mud to fine sand are particularly important for reconstructing past lacustrine depositional environments, because they usually reflect changes in flow regime from suspension to traction transport. These grain sizes are particularly challenging to identify in images but provide the best GIMS grain size estimates (RiveraHernandez et al., 2019). Thus, the GIMS analysis of the Murray formation documents systematic variations in grain size that were not captured from image-based analyses (Fig. 4). 
The distribution of grain sizes revealed by GIMS analysis records variations in depositional environment through time. The best constraints on depositional environment come from the well-studied Pahrump Hills outcrop, which contains near-shore lacustrine and deltaic facies (Grotzinger et al., 2015; Stack et al., 2019). Interpretations based on detailed analysis of image data demonstrate that near-shore lacustrine facies continue upward with a mix of laminated mudstones and sandstones (e.g., Stack et al., 2019). GIMS results support these interpretations, showing a predominance of GSR1 targets at the base of the Pahrump Hills section and increasing frequency of GSR2-GSR4 targets higher in the section (Fig. 4). GIMS grain size ranges remain mixed up through Marias Pass, and image grain size estimates are not available for most of this interval. GIMS data are consistent with a continuation of the near-shore lacustrine facies in this interval.

In the region near the Bridger Basin and Hartmann's Valley localities, many outcrops contain meter-scale cross stratification, abrupt stratal truncations, and concave curvilinear features indicative of large-scale dune bedforms (Fedo et al., 2018; Gwizd et al., 2019). For most of these rocks, grains are not resolved in MAHLI images suggesting they contain grains smaller than coarse silt (Gwizd et al., 2018). However, several rocks have resolvable grains, generally coarse silt to very fine sand in size, with a couple also containing sparse fine to medium sand sized grains (Gwizd et al., 2018). Comparatively, GIMS analyses reveal targets in all GSRs, suggesting grain sizes range from mud to potentially coarser than medium sand (Fig. 4). These results are consistent with the observed cross bedding and the interpretation that these sediments were deposited in fluvial or eolian environments rather than lacustrine environments (Fedo et al., 2018; Gwizd et al., 2018).

Rock targets from the Murray Buttes and lower Sebina interval dominantly fall within GSR1 and GSR2 with rare coarser-grained intervals. These grain size distributions and a 
paucity of cross stratification are consistent with facies similar to those at Pahrump and Marais Pass, e.g a near-shore lacustrine environment.

GIMS grain size ranges are finer from the upper part of Sebina through Paradise Hill, an interval dominated by GSR1 rocks (Fig. 4). GIMS identification of sandstones was rare, implying depositional environments with low flow speeds, generally consistent with lacustrine depositional environments. However, the presence of desiccation cracks at Old Soaker, located stratigraphically between Sebina and Paradise Hill, requires subaerial exposure (Fig. 6) (Stein et al., 2018). Similarly, the sedimentary facies in this stratigraphic interval appear variable in Mastcam images, leading to an overall interpretation that the rocks consist of heterogeneously interbedded mudstones, siltstones, and sandstones (i.e., heterolithic). Beds that have the appearance of sandstones in Mastcam images could be composed of sand-sized aggregates of mud-sized grains (for examples on Earth see Schieber and Southard, 2009 and Li and Schieber, 2018), which would produce uniform LIBS composition and thus fall within GSR1. Thus, the depositional environment is most consistent with shallow, near-shore lacustrine facies, possibly lacking a supply of sand-sized grains. In the immediate vicinity of Old Soaker, there are rocks with coarser grain sizes (up to GSR3; Fig. 4), perhaps demonstrating an influx of sand during a low stand in lake level. The relatively fine grain size of this sand is consistent with an eolian source, e.g. wind blowing across an exposed lakebed. The dominance of GSR1 rocks above Old Soaker and continuing to Paradise Hill suggests a return to lacustrine facies without a source of sand, as it is difficult to accumulate tens of meters of mm-scale laminated mud without the presence of standing water (Grotzinger et al., 2015).

The first evidence of a return to fluvial facies is marked by cross-stratified GSR4 rocks at Newport Ledge and Heron Island (Fig. 7). The coarse grain sizes and trough cross stratification in this area are similar to those at the Shaler outcrop of the Yellowknife Bay 
formation (Grotzinger et al., 2014; Anderson et al., 2015; Edgar et al., 2017; Rivera-

Hernández et al., 2019). The Shaler depositional environment was constrained by detailed image-based analyses of grain size, sorting, and shape, and bed-set geometries, leading to a fluvial interpretation (Edgar et al., 2017), with GIMS analyses demonstrating the dominance of GSR3-GSR4 targets (Rivera-Hernández et al., 2019). A similar analysis is not possible at Heron Island due to the outcrop geometry and a paucity of images. However, the abundance of trough cross stratification and GSR4 rocks from Newport Ledge to Heron Island, plus the similarities to the Shaler outcrop, suggest fluvial depositional environments.

In addition, the rocks in the Newport Ledge and Heron Island intervals show chemical enrichments in hydrated $\mathrm{Mg}$ sulfates, $\mathrm{Mn}, \mathrm{P}$, and Fe, although they are not generally coincident with each other (Meslin et al., 2018; Gasda et al., 2019; Lanza et al., 2019; Rapin et al., 2019). These enrichments are in contrast to the consistent mean composition of the Murray formation over nearly $300 \mathrm{~m}$ of stratigraphy (cf. Milliken et al., 2017; Frydenvang et al., 2018; Mangold et al., 2019). Changes in rock chemistry can influence GMEAN, and thus GIMS grain size ranges by either making the rocks more homogeneous or heterogeneous. However, rocks enriched in sulfate were excluded during the screening process, and the close correspondence of GSR3-GSR4 rocks and trough cross stratification suggest that the coarser GIMS results are not caused by the differences in elemental chemistry. Rather, results suggest that the chemical enrichments are related to a change in grain size and thus depositional environment. The influx of sand predicted by GIMS analysis is consistent with different sediment sources, and the likely fluvial environment implies different sources and fluxes of water. Either of these could result in elemental enrichments relative to the rest of the Murray formation. Similarly, the larger grain sizes suggest a higher permeability during early diagenesis. Newport Ledge to Heron Island sandstones could have been conduits for subsurface water flow, with diagenetic reactions providing the observed elemental 
enrichments. In either scenario, the GSR3-GSR4 GIMS results provide constraints on the processes causing the enrichments.

Above this interval, rocks in the Blunts Point interval return to GSR1 (Fig. 4) with the typical mean Murray formation composition (e.g., Frydenvang et al., 2018). The exclusive presence of GSR1 targets for 10's of meters of stratigraphy suggests the return to lacustrine depositional environments. The facies in this interval are more uniformly mudstone-like in appearance, in contrast to those from Sebina to Paradise Hill, consistent with a deeper lacustrine depositional environment.

\section{Implications for early Mars climate}

The predominance of rocks throughout the Murray formation interpreted as lacustrine facies suggests that liquid water was sustained on the martian surface for an extended period.

Based on sedimentation rates from lakes on Earth, it would take tens of thousands to millions of years to deposit $300 \mathrm{~m}$ of sediment, particularly when it is dominated by mudstone (e.g., Sadler, 1981; Grotzinger et al., 2015). Whether the interstratification of mudstones and sandstones is due to the presence of one lake that experienced water level changes, or if it represents multiple generations of lakes is an open question.

The diversity of depositional environments preserved in Gale crater imposes constraints on climate models for early Mars. On Earth, the association of sedimentary facies similar to those in the Murray formation occurs in a variety of climates from those that are tropical to those that are polar. Polar environments with annual mean temperatures below 0 ${ }^{\circ} \mathrm{C}$ can sustain episodic liquid melt-water flows into ice-covered lakes. Such lakes are common in the McMurdo Dry Valleys in Antarctica (e.g., Doran et al., 1994; Hendy, 2000). The presence of flowing and sustained liquid water on early Mars does not require annual mean temperatures above $0{ }^{\circ} \mathrm{C}$ even though prior interpretations of the Murray formation 
have argued for warm conditions (annual mean temperatures $>0{ }^{\circ} \mathrm{C}$ ) (Grotzinger et al., 2015; Mangold et al., 2019). Mangold et al. (2019) argued that, based on chemical index of alteration values comparable to those in regions with temperate climates on Earth, the climate of Gale crater must have been more like that of northern North America than like Antarctica. Sedimentological interpretations were based on the absence of glaciogenic sedimentary deposits and fabrics in the Murray formation, such as dropstones and coarse cobble or boulder conglomerates formed from tills, and evidence for ice wedge casts, indicative of strong oscillations in surface temperatures (Grotzinger et al., 2015).

Most facies predicted for perennially ice-covered lakes do not include tills (RiveraHernández et al., 2018). Rather, perennially ice-covered lake deposits consist predominantly of laminated mudstone with lenses of sand and/or dispersed sand grains (Rivera-Hernández et al., 2018), similar to the sandy mudstones at Marias Pass. Targets Wallace, Stenerson, and Wapiti at the Missoula outcrop in Marias Pass all show sand disseminated in a finer matrix, interpreted to be mud (Fig. 5). It is energetically difficult to transport sand grains into laterally extensive laminated mud, but sand grains can be blown onto an ice-covered lake and melt through the ice, falling into the laminated mud below. Thus, the sandy mudstones at Marias Pass suggest the presence of ice in this stratigraphic interval. Whether the ice was seasonal or perennial still remains uncertain as disseminated sand grains in laminated mud are only diagnostic of perennially ice-covered lakes if the sand is moderately- to well-sorted and associated with localized sand lenses that have inverse grading (Rivera-Hernández et al., 2018). The latter has yet to be identified in the Murray formation. However, if diagnostic perennially ice-covered lake facies are identified, these would suggest that mean annual temperatures remained below $0{ }^{\circ} \mathrm{C}$, but conditions were sufficiently warm to produce seasonal melting of frozen water (e.g., snow, glacial ice, or ground ice) to sustain liquid water in lakes (e.g., Wilson, 1967). 
Even if some of the lacustrine mudstones accumulated in perennially ice-covered lakes, no ice-wedge related sedimentary structures (e.g., ice wedge casts and cryoturbation features) were observed in the vicinity of the desiccation cracks at Old Soaker or the fluvial facies at Newport Ledge and Herron Island. Because both of these localities require liquid water exposed to the atmosphere, one would predict development of ice wedges if mean air temperature was below $0^{\circ} \mathrm{C}$ (e.g., Mackay, 1993). Thus, the present evidence suggests that the mean annual temperature was above the freezing point of water for these intervals of the Murray formation. In addition, the variations in depositional environment suggest that Mars had an active hydrological cycle, and Murray formation rocks record long-lived habitable environments, either at the surface when liquid water was present or in the near subsurface groundwater during possible drier intervals.

\section{Conclusions}

Grain sizes in the Murray formation, derived from ChemCam LIBS data using the GIMS technique, provide insights into changes in depositional environment through time.

Results demonstrate that the majority of rocks analyzed in the Murray formation are mudstones (GSR1-2 range), suggesting a nearly continuous presence of liquid water on the martian surface for tens of thousands to millions of years (e.g., Sadler, 1981; Grotzinger et al., 2015). Coarser grained rocks in GSR3-4 range suggests intervals of higher fluid flow velocities consistent with the presence of streams and possibly eolian dunes (e.g., Fedo et al., 2018; Gwizd et al., 2018, 2019). The presence of desiccation cracks suggests that there were periods of drying with a lowering of lake water-level (Stein et al., 2018). The diversity of rocks with varying grain sizes suggests a dynamic depositional setting early in martian history as preserved in Gale crater. 
GIMS results also document outcrop-scale variations in grain size that support sedimentological interpretations based on sedimentary structures. For example, where beds appear uniform, GIMS results confirm consistency in grain sizes. In contrast, where sedimentary structures suggest variations, GIMS confirms that the interpreted differences in sediment behavior can be attributed to grain size variations. Thus, the GIMS both provides confirmation of interpretations and can be used as a tool at localities where data for other forms of analysis, particularly high spatial resolution images, are not available.

\section{Acknowledgements}

This research was funded by the Chateaubriand STEM Fellowship sponsored by the Embassy of France in the United States, and by the Mars Science Laboratory Project through the NASA Mars Exploration Program. Collaborators in France who contributed to this research were funded by the Centre National d'Etudes Spatiales. We would like to thank the rest of the MSL Sedimentology and Stratigraphy working group, and the MAHLI and ChemCam instrument teams for constructive conversations and their fabulous datasets. All of the ChemCam LIBS data used in this manuscript can be found in Table S2 and freely online along with their corresponding RMI images through the PDS Geosciences node at https://pdsgeosciences.wustl.edu/missions/msl/chemcam.htm. All of the MAHLI and Mastcam images used in this manuscript are freely available through the PDS Cartography and Imaging Sciences node at https://pds-imaging.jpl.nasa.gov/volumes/msl.html. All GIMS results for the Murray formation from sols 750-1804 can be found in Table S3, Table S4, and archived online at https://doi.org/10.5281/zenodo.3605603.

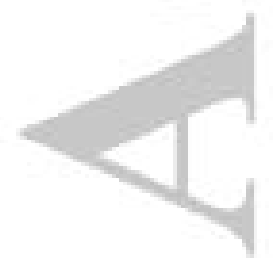




\section{References}

Anderson, R.B. \& Bell III, J. F. (2010). Geologic mapping and characterization of Gale Crater and implications for its potential as a Mars Science Laboratory landing site. Mars 5, pp. 76-128.

Anderson, R.B., Morris, R.V., Clegg, S.M., Bell, J.F., Wiens, R.C., Humphries, S.D., Mertzman, S.A., Graff, T.G. and McInroy, R. (2011). The influence of multivariate analysis methods and target grain size on the accuracy of remote quantitative chemical analysis of rocks using laser induced breakdown spectroscopy. Icarus, 215(2), pp.608-627.

Anderson, R., Bridges, J.C., Williams, A., Edgar, L., Ollila, A., Williams, J., Nachon, M., Mangold, N., Fisk, M., Schieber, J., Gupta, S. (2015). ChemCam results from the Shaler outcrop in Gale crater, Mars. Icarus 249, 2-21.

Banham, S. G., Gupta, S., Rubin, D.M., Watkins, J.A., Sumner, D.Y., Edgett, K.S., Grotzinger, J.P., Lewis, K.W., Edgar, L.A., Stack-Morgan, K.M., Barnes, R., Bell III, J.F., Day, M.D., Ewing, R.C., Lapotre, M.P.A, Stein, N.T., Rivera-Hernández, F., Vasavada, A.R. (2018) Sedimentology of an Ancient Aeolian Sandstone in the Lower Slope of Aeolis Mons, Stimson Formation, Gale Crater, Mars, Sedimentology, 65(4), 993-1042.

Bedford C.C., Bridges J.C., Schwenzer S.P., Wiens R.C., Rampe E., Frydenvang J., and Gasda P.J. (2019) Alteration trends and geochemical source region characteristics preserved in the fluviolacustrine sedimentary record of Gale crater, Mars. Geochim. Cosmochim. Acta 246, 234-266, doi:10.1016/j.g 2018.11.031.

Bell, J.F., Godber, A., McNair, S., Caplinger, M.A., Maki, J.N., Lemmon, M.T., Van Beek, J., Malin, M.C., Wellington, D., Kinch, K.M. and Madsen, M.B. (2017). The Mars Science Laboratory Curiosity Rover Mast Camera (Mastcam) Instruments: Pre-Flight 
and In-Flight Calibration, Validation, and Data Archiving. Earth and Space Science, $4(7), 396-452$

Bristow, T.F., Rampe, E.B., Achilles, C.N., Blake, D.F., Chipera, S.J., Craig, P., Crisp, J.A., Des Marais, D.J., Downs, R.T., Gellert, R., Grotzinger, J.P., Gupta, S., Hazen, R.M., Horgan, B., Hogancamp, J.V., Mangold N., Mahaffy, P.R., McAdam, A.C., Ming, D.W., Morookian, J.M., Morris, R.V., Morrison, S.M., Treiman, A.H., Vaniman, D.T., Vasavada, A.R., Yen, A.S. (2018) Clay Mineral Diversity and Abundance in Sedimentary Rocks of Gale Crater, Mars. Science advances, 4(6), eaar3330.

Clegg, S. M., Sklute, E., Dyar, M. D., Barefield, J. E., \& Wiens, R. C. (2009). Multivariate analysis of remote laser-induced breakdown spectroscopy spectra using partial least squares, principal component analysis, and related techniques. Spectrochimica Acta Part B: Atomic Spectroscopy, 64(1), 79-88.

Clegg, S.M., Wiens, R.C., Anderson, R., Forni, O., Frydenvang, J., Lasue, J., Cousin, A., Payré, V., Boucher, T., Dyar, M.D. and McLennan, S.M. (2017). Recalibration of the Mars Science Laboratory ChemCam instrument with an expanded geochemical database. Spectrochimica Acta Part B: Atomic Spectroscopy, 129, pp.64-85.

Davis, K., J. Herman, M. Maksymuk, J. Wilson, P. Chu, K. Burke, L. Jandura, and K. Brown (2012), Mars Science Laboratory’s dust removal tool, Aerospace Mechanisms Symposium 41, NASA Conf. Proc. NASA/CP-2012-217653, 279-292.

Doran, P. T., Wharton, R. A., \& Lyons, W. B. (1994). Paleolimnology of the McMurdo dry valleys, Antarctica. Journal of Paleolimnology, 10(2), 85-114.

Edgar, L.A., Gupta, S., Rubin, D.M., Lewis, K.W., Kocurek, G.A., Anderson, R.B., Bell, J.F., Dromart, G., Edgett, K.S., Grotzinger, J.P. and Hardgrove, C. (2017). Shaler: In situ analysis of a fluvial sedimentary deposit on Mars. Sedimentology, 65(1), 96-122. 
Edgett, K.S., Yingst, R.A., Ravine, M.A., Caplinger, M.A., Maki, J.N., Ghaemi, F.T.,

Schaffner, J.A., Bell, J.F., Edwards, L.J., Herkenhoff, K.E. and Heydari, E. (2012).

Curiosity's Mars hand lens imager (MAHLI) investigation. Space science reviews, 170(1-4), pp.259-317.

Edgett, K.S., Caplinger, M.A., Maki, J.N., Ravine, M.A., Ghaemi, F.T., McNair, S., Herkenhoff, K.E., Duston, B.M., Willson, R.G., Yingst, R.A. and Kennedy, M.R. (2015). Curiosity's robotic arm-mounted Mars Hand Lens Imager (MAHLI):

Characterization and calibration status (Vol. 1, No. 19, p. 2). MSL MAHLI Technical Report.

Farmer, J. D., \& Des Marais, D. J. (1999). Exploring for a record of ancient Martian life. Journal of Geophysical Research: Planets, 104(E11), 26977-26995.

Fedo, C.M., Grotzinger, J.P., Gupta, S., Fraeman, A., Edgar, L., Edgett, K., Stein, N., Rivera-Hernandez, F., Lewis, K., Stack, K.M., House, C., Rubin, D., \& Vasavada, A.R. (2018) Sedimentology and stratigraphy of the Murray formation, Gale crater, Mars. In the 49th Lunar and Planetary Science Conference, Abstract \#2078.

Fraeman, A.A., Arvidson, R.E., Catalano, J.G., Grotzinger, J.P., Morris, R.V., Murchie, S.L., Stack, K.M., Humm, D.C., McGovern, J.A., Seelos, F.P. and Seelos, K.D. (2013). A hematite-bearing layer in Gale Crater, Mars: Mapping and implications for past aqueous conditions. Geology, 41(10), pp.1103-1106.

Fraeman, A.A., Ehlmann, B.L., Arvidson, R.E., Edwards, C.S., Grotzinger, J.P., Milliken, R.E., Quinn, D.P. and Rice, M.S. (2016). The stratigraphy and evolution of lower Mount Sharp from spectral, morphological, and thermophysical orbital data sets. Journal of Geophysical Research: Planets, 121(9), pp.1713-1736.

Fraeman, A.A., Edgar, L.A., Grotzinger, J.P., Vasavada, A.R., Johnson, J.R., Wellington, D.F., Fox, V.K., Sun, V.Z., Hardgrove, C.J., Horgan, B.N., House, C.H., Johnson, 
S.S., Stack Morgan, K.M.,, Rampe, E.B., Thompson, L.M., Wiens, R.C., Williams,

A.J. (2018) Curiosity’s Investigation at Vera Rubin Ridge. In the 2018 Lunar and Planetary Science Conference, Abstract \#1557.

Frydenvang, J., Gasda, P.J., Hurowitz, J.A., Grotzinger, J.P., Wiens, R.C., Newsom, H.E., Edgett, K.S., Watkins, J., Bridges, J.C., Maurice, S. and Fisk, M.R. (2017).

Diagenetic silica enrichment and late-stage groundwater activity in Gale crater, Mars. Geophysical Research Letters, 44(10), pp.4716-4724.

Frydenvang, J., Mangold, N., Wiens, R. C., Clark, B. C., Fraeman, A. A., Forni, O., ... \& Calef, F. (2018). Geochemical variations observed with the ChemCam instrument on Vera Rubin Ridge in Gale crater, Mars. In the $49^{\text {th }}$ Lunar and Planetary Science Conference, Abstract \#2310.

Jackson, R. S. (2016). Investigation of Aqueous Processes in the Valle Grande Paleo-Lake, Valles Caldera as a Martian Analog; Chemcam Investigation of the John Klein and Cumberland Drill Holes and Tailings, Gale Crater, Mars (master's thesis). University of New Mexico, Albuquerque, New Mexico.

Gasda, P. J., Lanza, N., Meslin, P. Y., Forni, O., L'Haridon, J., Fischer, W. W., et al. (2019). High-Mn Sandstone as Evidence for Oxidized Conditions in Gale Crater Lake. In the $49^{\text {th }}$ Lunar and Planetary Science Conference, Abstract \#1620.

Gini, C. (1921). Measurement of inequality of incomes. The Economic Journal, 31(121), pp.124-126.

Grant, J.A., Wilson, S.A., Mangold, N., Calef, F. and Grotzinger, J.P. (2014). The timing of alluvial activity in Gale crater, Mars. Geophysical Research Letters, 41(4), pp.11421149.

Grotzinger, J. P., Crisp, J., Vasavada, A. R., Anderson, R. C., et al. (2012). Mars Science Laboratory mission and science investigation. Space science reviews, 170(1-4), 5-56. 
Grotzinger, J.P., Sumner, D.Y., Kah, L.C., Stack, K., Gupta, S., Edgar, L., Rubin, D., Lewis, K., Schieber, J., Mangold, N. and Milliken, R. (2014). A habitable fluvio-lacustrine environment at Yellowknife Bay, Gale Crater, Mars. Science, 343(6169), p.1242777.

Grotzinger, J. P., Gupta, S., Malin, M. C., Rubin, D. M., Schieber, J., Siebach, K., et al (2015). Deposition, exhumation, and paleoclimate of an ancient lake deposit, Gale crater, Mars. Science, 350(6257), aac7575.

Gwizd, S., Fedo, C., Grotzinger, J., Edgett, K., Rivera-Hernandez, F., \& Stein, N. (2018). Depositional History of the Hartmann's Valley Member, Murray Formation, Gale Crater, Mars. In the $49^{\text {th }}$ Lunar and Planetary Science Conference, Abstract \#2150.

Gwizd, S., Fedo, C., Grotzinger, J., Edgett, K., Gupta, S., Stack, K. M., Banham, S., Edgar, L.A., \& Sumner, D. (2019). Toward a Greater Understanding of Cross-Stratified Facies in the Hartmann's Valley Member of the Murray Formation, Gale Crater, Mars. In the Ninth International Conference on Mars, Abstract \#6183.

Hendy, C. H. (2000). Late Quaternary lakes in the McMurdo Sound region of Antarctica. Geografiska Annaler: Series A, Physical Geography, 82(2-3), 411-432. https://doi.org/10.1111/j.0435-3676.2000.00131.x

Kah, L. C., Stack, K. M., Eigenbrode, J. L., Yingst, R. A., \& Edgett, K. S. (2018) Syndepositional precipitation of calcium sulfate in Gale Crater, Mars. Terra Nova. doi: $10.1111 /$ ter.12359

Kronyak, R. E., Kah, L. C., Edgett, K. S., VanBommel, S. J., Thompson, L. M., Wiens, R. C., ... \& Nachon, M. (2019). Mineral-filled fractures as indicators of multigenerational fluid flow in the Pahrump Hills member of the Murray formation, Gale crater, Mars. Earth and Space Science, 6(2), 238-265.

Le Deit, L., Hauber, E., Fueten, F., Pondrelli, M., Rossi, A.P. and Jaumann, R. (2013). Sequence of infilling events in Gale Crater, Mars: Results from morphology, 
stratigraphy, and mineralogy. Journal of Geophysical Research: Planets, 118(12), pp.2439-2473.

Le Mouélic, S., Gasnault, O., Herkenhoff, K.E., Bridges, N.T., Langevin, Y., Mangold, N., Maurice, S., Wiens, R.C., Pinet, P., Newsom, H.E. and Deen, R.G. (2015). The ChemCam Remote Micro-Imager at Gale crater: Review of the first year of operations on Mars. Icarus, 249, pp.93-107.

L'Haridon, J., Mangold, N., Meslin, P. Y., Johnson, J. R., Rapin, W., Forni, O., ... \& Le Deit, L. (2018). Chemical variability in mineralized veins observed by ChemCam on the lower slopes of Mount Sharp in Gale crater, Mars. Icarus, 311, 69-86.

Li, Z., \& Schieber, J. (2018). Composite particles in mudstones: examples from the late cretaceous Tununk shale member of the Mancos shale formation. Journal of Sedimentary Research, 88(12), 1319-1344.

Mackay, J. R. (1993). Air temperature, snow cover, creep of frozen ground, and the time of ice-wedge cracking, western Arctic coast. Canadian Journal of Earth Sciences, 30(8), $1720-1729$.

Malin, M.C., Ravine, M.A., Caplinger, M.A., Ghaemi, F.T., Schaffner, J.A., Maki, J.N., Bell, J.F., Cameron, J.F., Dietrich, W.E., Edgett, K.S. and Edwards, L.J. (2017). The Mars Science Laboratory (MSL) Mast cameras and Descent imager: I. Investigation and instrument descriptions. Earth and Space Science, 4(8), 506-539.

Mangold, N., Thompson, L.M., Forni, O., Williams, A.J., Fabre, C., Le Deit, L., Wiens, R.C., Williams, R., Anderson, R.B., Blaney, D.L. and Calef, F. (2016). Composition of conglomerates analyzed by the Curiosity rover: Implications for Gale Crater crust and sediment sources. Journal of Geophysical Research: Planets, 121(3), pp.353-387.

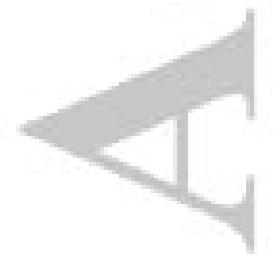


Mangold, N., Schmidt, M. E., Fisk, M. R., Forni, O., McLennan, S. M., Ming, D. W., Sautter, V., Sumner, D., et al. (2017). Classification scheme for sedimentary and igneous rocks in Gale crater, Mars. Icarus, 284, 1-17.

Mangold N., Dehouck E., Fedo C., Forni O., Achilles C., Bristow T., Frydenvang J., Gasnault O., L’Haridon J., Le Deit L., Maurice S., McLennan S.M., Meslin P.-Y., Morrison S., Newsom H.E., Rampe E., Rivera-Hernandez F., Salvatore M., and Wiens R.C. (2019) Chemical alteration of fine-grained sedimentary rocks at Gale crater. Icarus, 321, 619-631, doi: 10.1016/j.icarus.2018.11.004.

Maurice, S., Wiens, R.C., Saccoccio, M., Barraclough, B., Gasnault, O., Forni, O., et al., 2012a. The ChemCam instrument suite on the Mars Science Laboratory (MSL) rover: science objectives and mast unit description. Space Sci. Rev. 170 (1-4), 95-166.

McCanta, M. C., Dobosh, P. A., Dyar, M. D., \& Newsom, H. E. (2013). Testing the veracity of LIBS analyses on Mars using the LIBSSIM program. Planetary and Space Science, $81,48-54$.

McCanta, M.C., Dyar, M.D., Dobosh, P.A., Davidson, G.R., Hill, C.A., Wolgemuth, K., Romanowicz, B., Hirschmann, M., Kellogg, L., Manga, M. and Mukhopadhyay, S. (2017). Extracting Bulk Rock Properties from Microscale Measurements:

Subsampling and Analytical Guidelines. GSA Today, 27(7).

Meslin, P. Y., Gasda, P., L'Haridon, J., Forni, O., Lanza, N., Lamm, S., et al. (2018). Detection of Hydrous Manganese and Iron Oxides with Variable Phosphorus and Magnesium Contents in the Lacustrine Sediments of the Murray Formation, Gale, Mars. In the $49^{\text {th }}$ Lunar and Planetary Science Conference, Abstract \#1447.

Milliken, R. E., Hurowitz, J. A., Grotzinger, J. P., Wiens, R. C., Gellert, R., \& Vasavada, A. (2017). Of elements, minerals, and rocks: Mt. Sharp as a key reference section in 
assessing the climatic evolution of Mars. In the $48^{\text {th }}$ Lunar and Planetary Science Conference, Abstract \#2189.

Minitti, M. E., Malin, M. C., Van Beek, J. K., Caplinger, M., Maki, J. N., Ravine, M., Calef III, F.J., Edgar, L.A., Harker, D., Herkenhoff, K.E., Kah, L. C. et al. (2019). Distribution of primary and secondary features in the Pahrump Hills outcrop (Gale crater, Mars) as seen in a Mars Descent Imager (MARDI) "sidewalk" mosaic. Icarus. https://doi.org/10.1016/j.icarus.2019.03.005

Morris, R.V., Vaniman, D.T., Blake, D.F., Gellert, R., Chipera, S.J., Rampe, E.B., Ming, D.W., Morrison, S.M., Downs, R.T., Treiman, A.H. and Yen, A.S. (2016). Silicic volcanism on Mars evidenced by tridymite in high-SiO2 sedimentary rock at Gale crater. Proceedings of the National Academy of Sciences, 113(26), pp.7071-7076.

Nachon, M., Clegg, S.M., Mangold, N., Schröder, S., Kah, L.C., Dromart, G., Ollila, A., Johnson, J.R., Oehler, D.Z., Bridges, J.C. and Le Mouélic, S. (2014). Calcium sulfate veins characterized by ChemCam/Curiosity at Gale crater, Mars. Journal of Geophysical Research: Planets, 119(9), pp.1991-2016.

Nachon, M., Mangold, N., Forni, O., Kah, L.C., Cousin, A., Wiens, R.C., Anderson, R., Blaney, D., Blank, J.G., Calef, F. and Clegg, S.M. (2017). Chemistry of diagenetic features analyzed by ChemCam at Pahrump Hills, Gale crater, Mars. Icarus, 281, pp.121-136.

Nellessen, M.A., Baker, A.M., Newsom, H.E., Jackson, R.S., Nachon, M., RiveraHernandez, F., Williams, J., Wiens, R.C., Frydenvang, J., Gasda, P., Lanza, N., Ollila, A., Clegg, S., Gasnault, O., Maurice, S., Meslin, P.Y., Cousin, A., Rapin, W., Lasue, J., Forni, O., L’Haridon, J, Blaney, D., Payré, V., Mangold, N., LeDeit, L., Edgett, K., Anderson, R. Distribution and Analysis of Calcium Sulfate-Cemented Sandstones 
along the MSL Traverse, Gale Crater, Mars. (2018). In the 49th Lunar and Planetary Science Conference, Abstract \#2858.

Newsom, H., Edgett, K., Wiens, R., Mangold, N., Schieber, J., Stack, K., Rapin, W., Stein, N., Rivera-Hernandez, F. (2017). Imaging and chemical signatures of sandstone cemented by calcium sulfate, in the Stimson and Murray formation rocks of Gale Crater, Mars, International Meeting of Sedimentology 33, Toulouse, France.

Palucis, M.C., Dietrich, W.E., Hayes, A.G., Williams, R.M., Gupta, S., Mangold, N., Newsom, H., Hardgrove, C., Calef, F. and Sumner, D.Y. (2014). The origin and evolution of the Peace Vallis fan system that drains to the Curiosity landing area, Gale Crater, Mars. Journal of Geophysical Research: Planets, 119(4), pp.705-728.

Rampe, E.B., Ming, D.W., Blake, D.F., Bristow, T.F., Chipera, S.J., Grotzinger, J.P., Morris, R.V., Morrison, S.M., Vaniman, D.T., Yen, A.S. and Achilles, C.N. (2017). Mineralogy of an ancient lacustrine mudstone succession from the Murray formation, Gale crater, Mars. Earth and Planetary Science Letters, 471, 172-185.

Rapin, W., Ehlmann, B., Dromart, G., Schieber, J., Thomas, N., Fischer, W., Fox, V., et al. (2019) An interval of high salinity in ancient Gale crater lake on Mars. Nature Geoscience, 12(11), 889-895

Rivera-Hernández, F., Sumner, D. Y., Mackey, T.J., Hawes, I., Andersen, D.T. (2018) In a PICL: The sedimentary deposits and facies of perennially ice-covered lakes.

Sedimentology. doi: 10.1111/sed.12522

Rivera-Hernández, F., Sumner, D. Y., Mangold N., Stack, K.M., Newsom, H., Williams, A., Nachon, M., L’Haridon, J., Gasnault, O., Wiens, R.W., Maurice, S., MSL Science Team. (2019) Using ChemCam LIBS data to constrain grain size in rocks on Mars: Proof of concept and application to rocks at Yellowknife Bay and Pahrump Hills, Gale crater, Icarus. doi: 10.1016/j.icarus.2018.10.023 
Sadler, P. M. (1981). Sediment accumulation rates and the completeness of stratigraphic sections. The Journal of Geology, 89(5), 569-584.

Schieber, J., \& Southard, J. B. (2009). Bedload transport of mud by floccule ripples-Direct observation of ripple migration processes and their implications. Geology, 37(6), 483486.

Schieber, J. (2018) How small is it? Pushing MAHLI to the limit in the search for mudstones at Gale crater, Mars. In the 49th Lunar and Planetary Science Conference, Abstract \#1100.

Sivakumar, P., Taleh, L., Markushin, Y., \& Melikechi, N. (2014). Packing density effects on the fluctuations of the emission lines in laser-induced breakdown spectroscopy. Spectrochimica Acta Part B: Atomic Spectroscopy, 92, 84-89.

Smith, D. E., Zuber, M. T., Frey, H. V., Garvin, J. B., Head, J. W., Muhleman, D. O., ... \& Banerdt, W. B. (2001). Mars Orbiter Laser Altimeter: Experiment summary after the first year of global mapping of Mars. Journal of Geophysical Research: Planets, 106(E10), 23689-23722.

Stack, K.M., Grotzinger, J.P., Rubin, D.M., Gupta, S., Sumner, D.Y., Schieber, J., Lamb, M.P. (2018) Evidence for plunging river plume deposits in the Pahrump Hills member of the lower Murray formation, Gale crater, Mars. doi:10.1111/sed.12558

Stein, N., Grotzinger, J.P., Schieber, J., Mangold, N., Hallet, B., Newsom, H., Stack, K.M., Berger, J.A., Thompson, L., Siebach, K.L., Cousin, A., Le Mouélic, S., Minitti, M., Sumner, D.Y., Fedo, C., House, C.H., Gupta, S., Vasavada, A.R., Gellert, R., Wiens, R.C., Frydenvan, J., Forni, O., Meslin, P.Y., Payré, V., Dehouck, E. (2018).

Desiccation cracks provide evidence of lake drying on Mars, Sutton Island member, Murray formation, Gale Crater. Geology, 46(6), 515-518. 
Summons, R.E., Amend, J.P., Bish, D., Buick, R., Cody, G.D., Des Marais, D.J., Dromart, G., Eigenbrode, J.L., Knoll, A.H. and Sumner, D.Y. (2011). Preservation of martian organic and environmental records: final report of the Mars Biosignature Working Group. Astrobiology, 11(2), pp.157-181.

Sun, V.Z., Stack, K.M., Kah, L.C., Thompson, L., Fischer, W., Williams, A.J., Johnson, S. S., Wiens, R.C., Kronyak, R.E., Nachon, M., House, C.H., VanBommel, S. (2019). Late-stage diagenetic concretions in the Murray formation, Gale crater, Mars. Icarus, 321, 866-890.

Thomson, B.J., Bridges, N.T., Milliken, R., Baldridge, A., Hook, S.J., Crowley, J.K., Marion, G.M., de Souza Filho, C.R., Brown, A.J. and Weitz, C.M. (2011). Constraints on the origin and evolution of the layered mound in Gale Crater, Mars using Mars Reconnaissance Orbiter data. Icarus, 214(2), pp.413-432.

Watkins, J.A., Grotzinger, J., Stein, N., Banham, S.G., Gupta, S., Rubin, D., Stack, K.M. and Edgett, K.S. (2016) Paleotopography of Erosional Unconformity, Base of Stimson Formation, Gale Crater, Mars. In the 47th Lunar and Planetary Science Conference, Abstract \# 2939.

Wentworth, C.K. (1922). A scale of grade and class terms for clastic sediments. The Journal of Geology, 30(5), pp.377-392.

Wiens, R.C., Maurice, S., Barraclough, B., Saccoccio, M., Barkley, W.C., Bell, J.F., Bender, S., Bernardin, J., Blaney, D., Blank, J. and Bouyé, M., et al. (2012). The ChemCam instrument suite on the Mars Science Laboratory (MSL) rover: Body unit and combined system tests. Space Science Reviews, 170(1-4), pp.167-227.

Wiens, R. C., Maurice, S., Lasue, J., Forni, O., Anderson, R. B., Clegg, S., et al. (2013). Preflight calibration and initial data processing for the ChemCam laser-induced 
breakdown spectroscopy instrument on the Mars Science Laboratory rover.

Spectrochimica Acta Part B: Atomic Spectroscopy, 82, 1-27.

Wilson, A. T. (1967). The lakes of the McMurdo dry valleys. Tuatara, 15(3), 152-164.

Yen, A.S., Ming, D.W., Vaniman, D.T., Gellert, R., Blake, D.F., Morris, R.V., Morrison, S.M., Bristow, T.F., Chipera, S.J., Edgett, K.S. and Treiman, A.H. (2017). Multiple stages of aqueous alteration along fractures in mudstone and sandstone strata in Gale Crater, Mars. Earth and Planetary Science Letters, 471, pp.186-198.

Yingst, R. A., Edgett, K. S., Kennedy, M. R., Krezoski, G. M., McBride, M. J., Minitti, M. E., Ravine, M. A., and Williams, R. M. E. (2016). MAHLI on Mars: lessons learned operating a geoscience camera on a landed payload robotic arm. Geoscientific

Instrumentation, Methods and Data Systems, 5, 205-217.

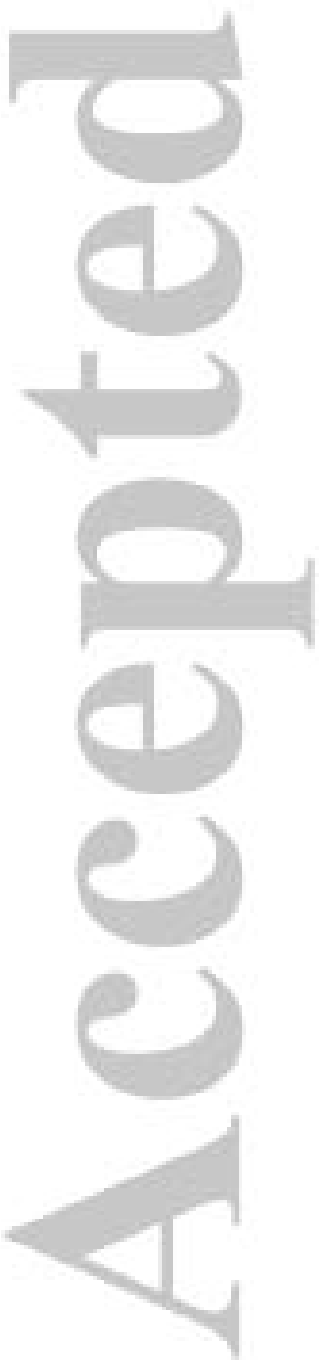



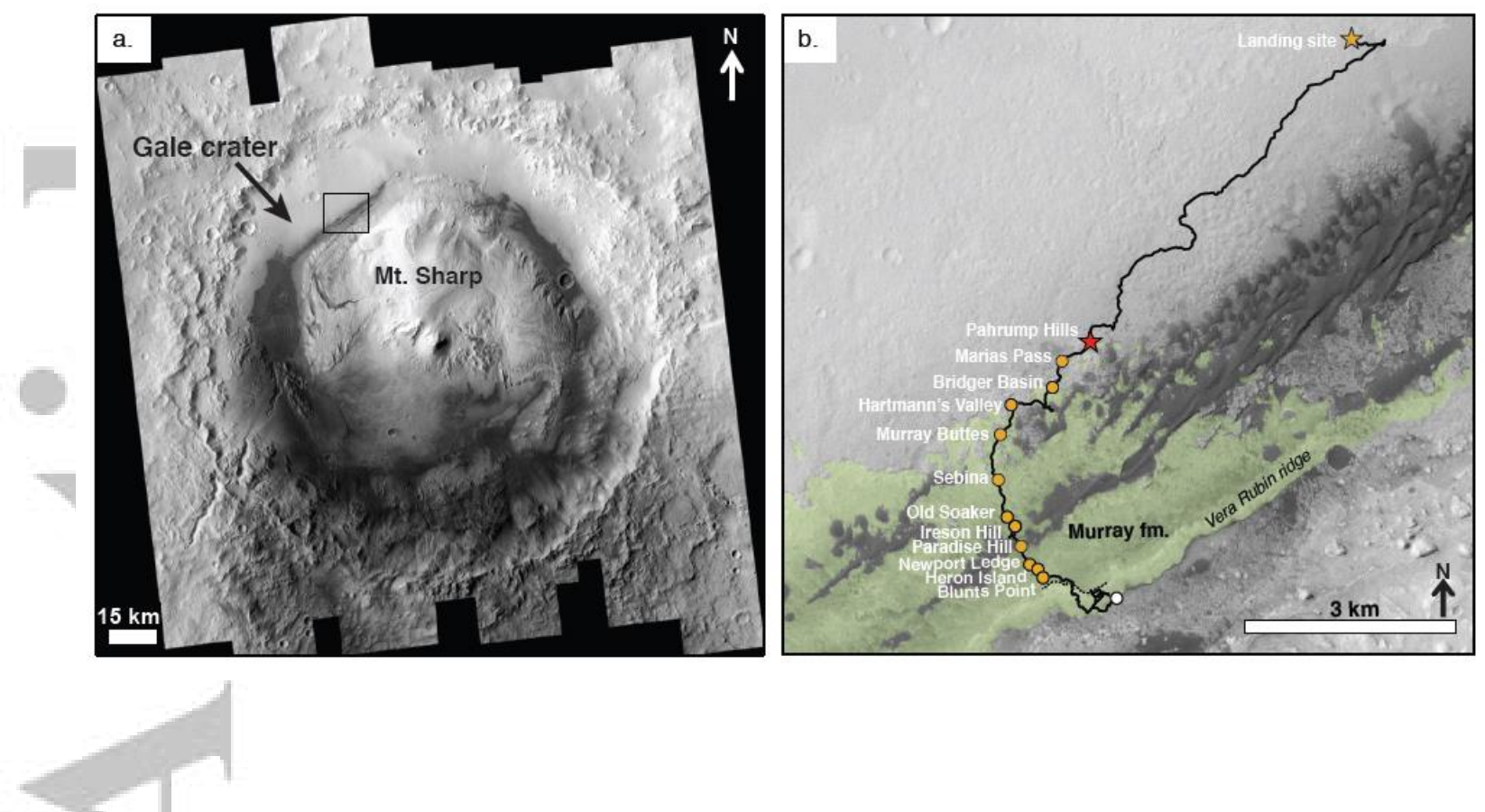

Figure 1. (a) A Context Camera image mosaic of Gale crater (Anderson and Bell, 2010). The black box highlights the area shown in Fig. 1b. (b) The Curiosity field site. The black line shows the rover traverse between landing and Sol 2150. The green highlighted area is the mapped areal extent of the exposed Murray formation (Fraeman et al., 2016; Stack et al., 2019). The red star marks the location where the Murray formation was first encountered. The orange points mark important named localities within the stratigraphy of the Murray formation (Figure 2)."

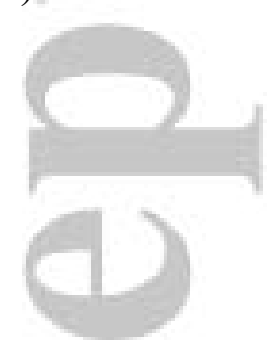



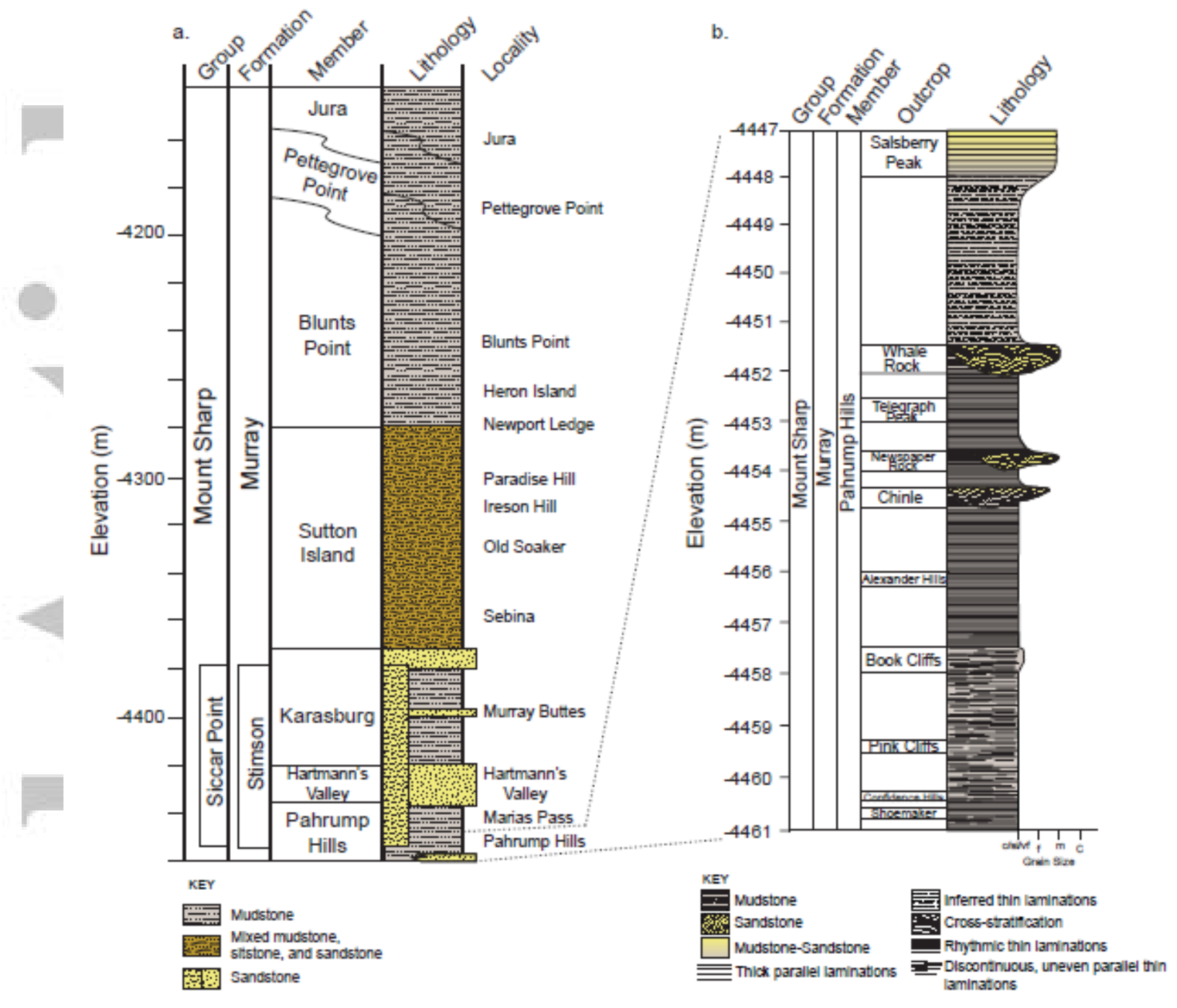

Figure 2. (a) The full stratigraphic column of the Murray formation as of May 2019. The dashed lines mark the top and bottom elevation of the stratigraphic column of the Pahrump Hills locality shown in (b). (b) Detailed stratigraphic column of the Pahrump Hills member modified from Stack et al. (2019). 


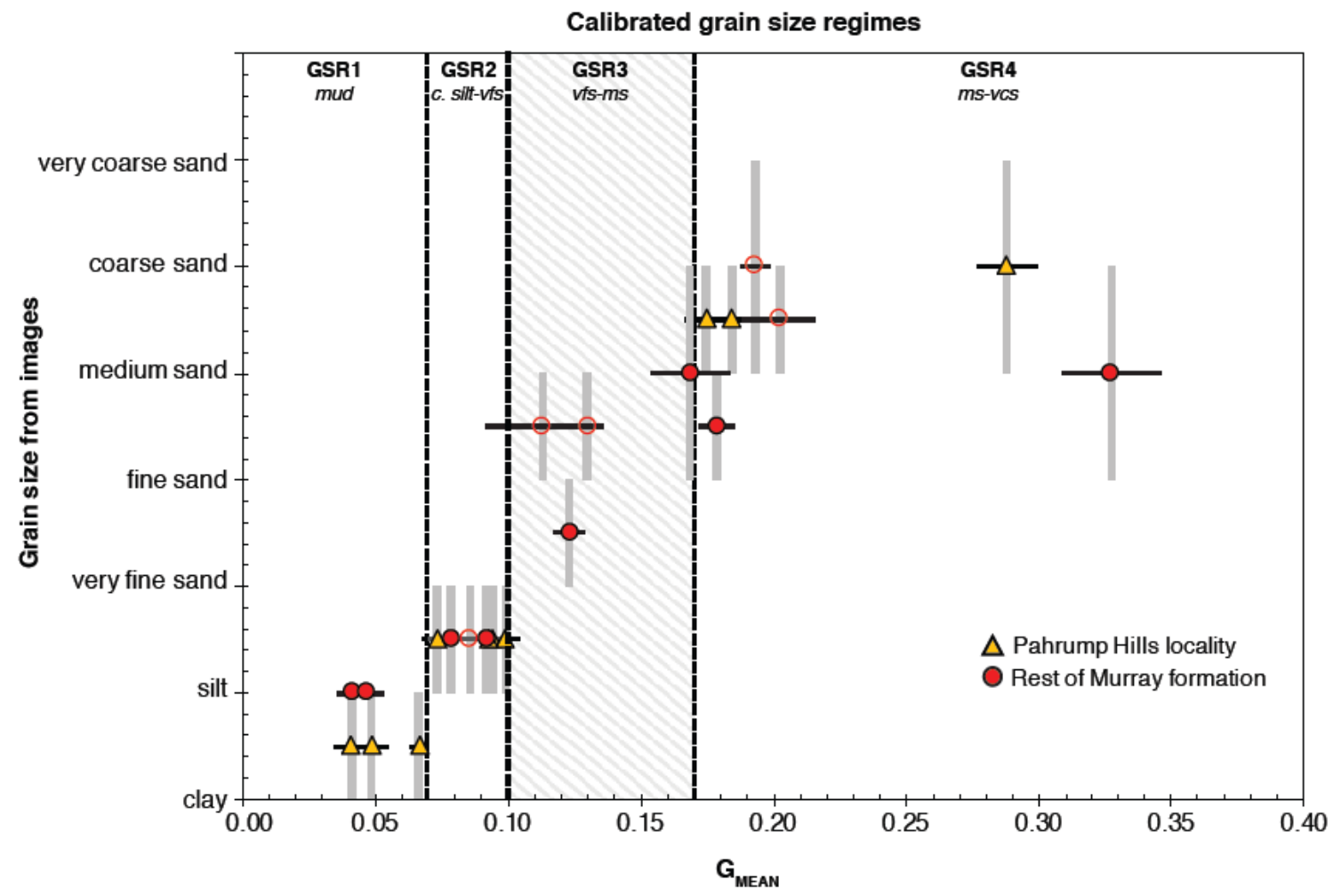

Figure 3. Grain size from image-data versus $G_{M E A N}$ for the rock standards from the Murray formation. The four grain size regimes (GSRs) were defined during the calibration procedure (see Section 4.1; Table S1). GSR3 has a hashed pattern because its bounds are not well constrained (see Section 4.1). Each data point includes a $1 \sigma$ STDr black horizontal error bar and a grey vertical box showing the range of grain sizes resolved in the rock standards in MAHLI (open symbols) and RMI images (closed symbols). Most samples may include finer grain sizes that could not be resolved in the images. 

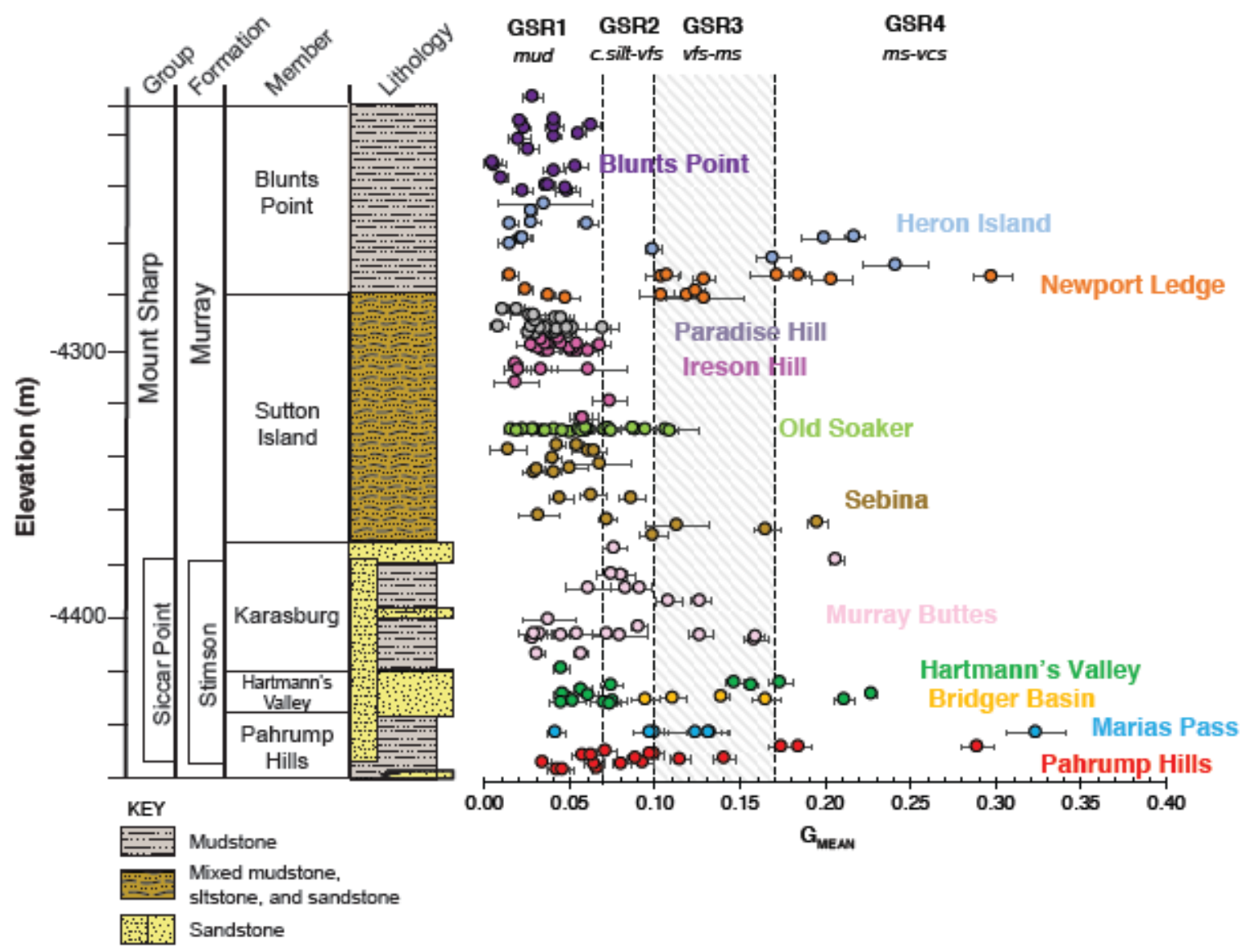

Figure 4. GMEAN for rocks used in the GIMS analysis plotted with the stratigraphic column of the Murray formation up to the Blunts Point member. Each GMEAN data point includes a $1 \sigma$ STDr black horizontal error bar. All localities discussed in this manuscript are marked parallel to the plot at their approximate elevations in the stratigraphy. The four GSRs were defined during the calibration procedure (see Section 4.1; Table S1). GSR3 has a hashed pattern because its bounds are not well constrained (see Section 4.1). 


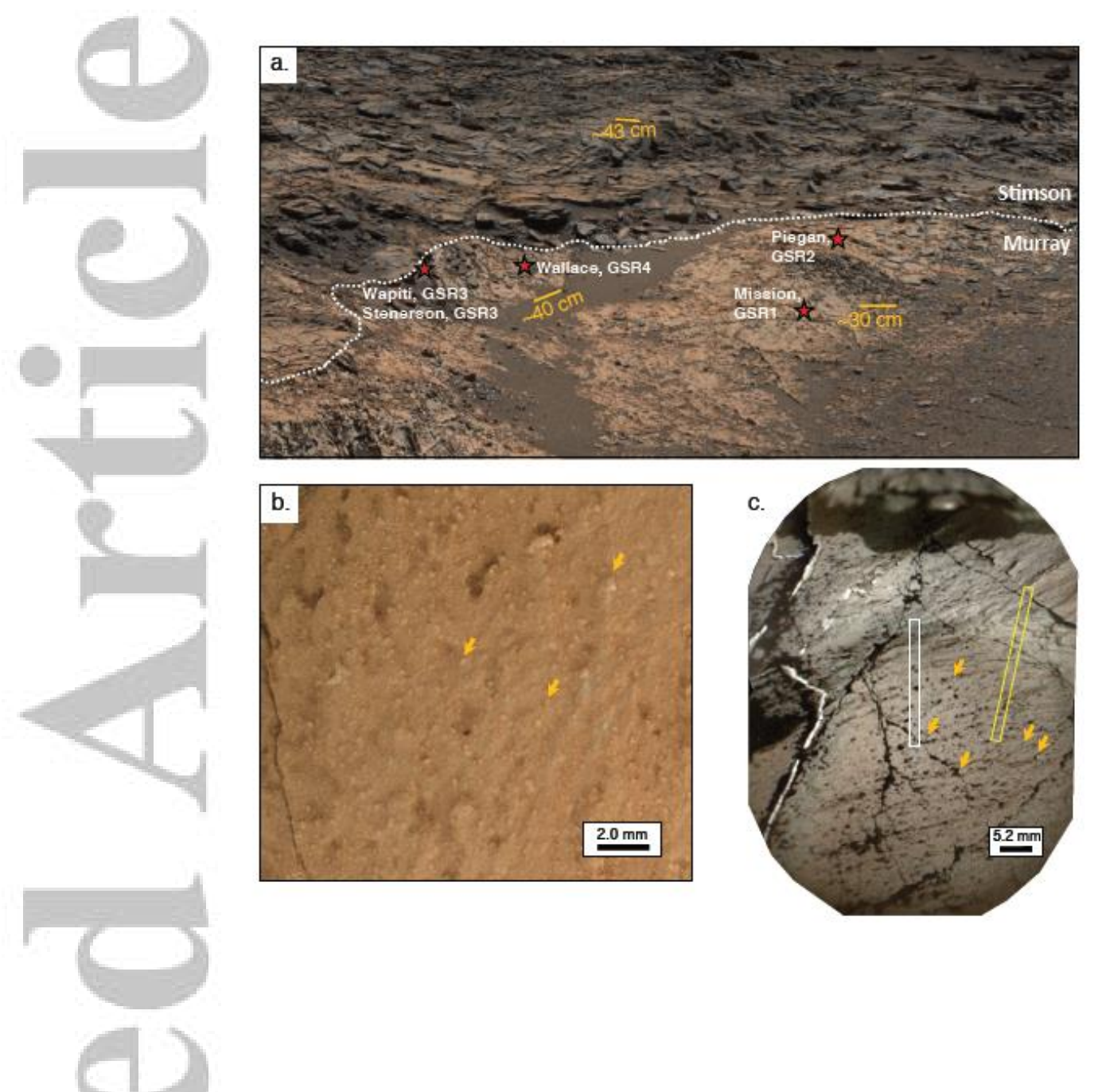

Figure 5. (a) Mastcam mosaic of the Missoula outcrop at Marias Pass acquired on Sol 992 (sequence mcam04393). The white dashed trace marks the approximate location of the stratigraphic contact between the Murray and Stimson formations (Watkins et al., 2016). The red stars are the approximate locations of ChemCam analyses. (b) Cropped MAHLI image of the ChemCam target Wallace from Sol 999 at $2 \mathrm{~cm}$ standoff (0999MH0004970050204810C00). Wallace consists of mainly medium sand sized grains dispersed in a finer-grained framework. The orange arrows highlight resolvable grains in the rock. (c) RMI image mosaic taken on Sol 1030 of a Murray formation rock face that includes the ChemCam analyses Wapiti and Stenerson (white and yellow rectangles, respectively). The orange arrows indicate medium sand-sized grains. The RMI image product was merged with a Mastcam image taken on Sol 1031 (sequence mcam04504) to provide color. 


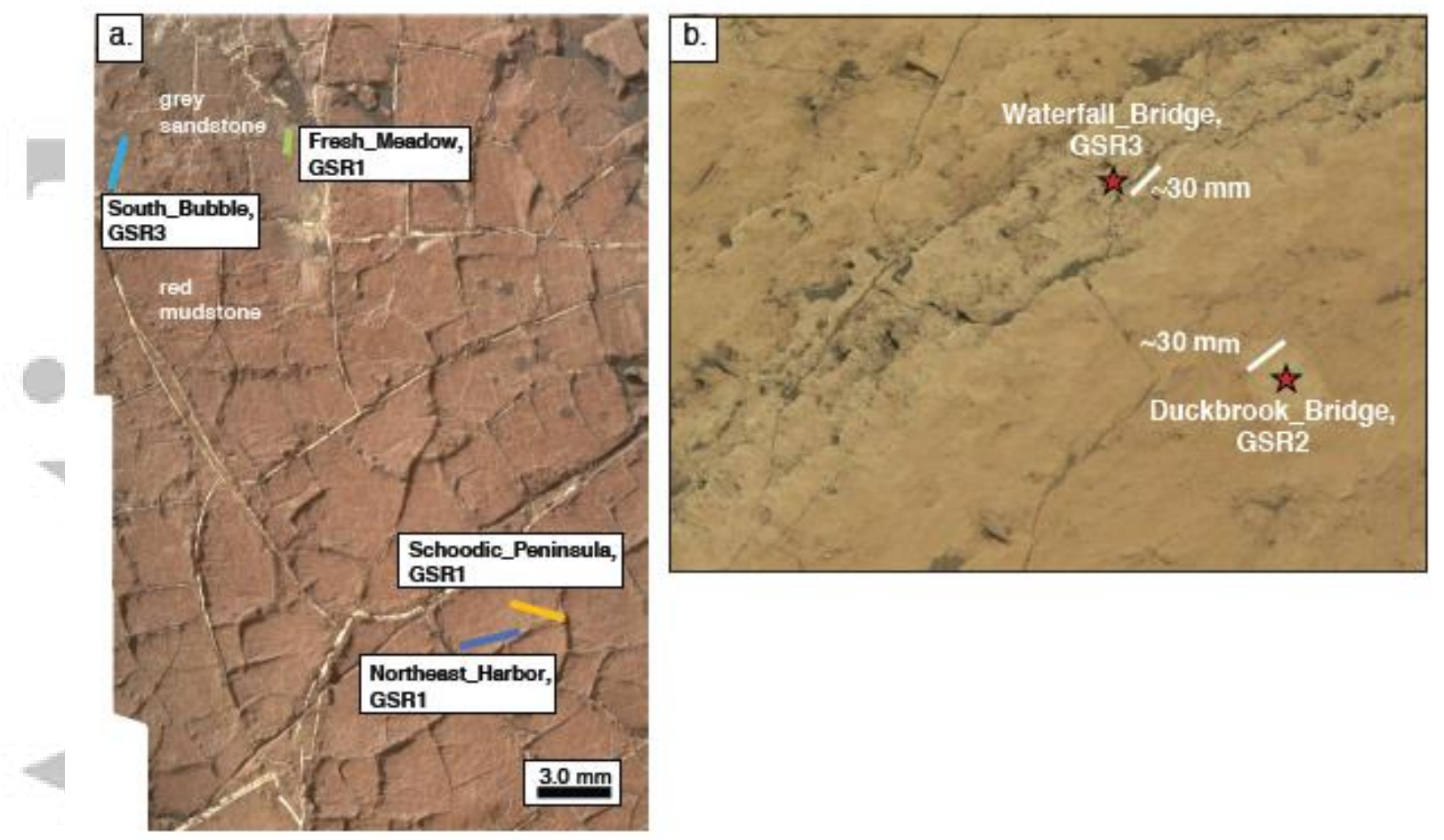

Figure 6. (a) MAHLI image mosaic of the rock exposure Old Soaker taken at $\sim 25 \mathrm{~cm}$ standoff on Sol 1566. The colored solid lines indicate the approximate location of ChemCam targets. This is a mosaic of MAHLI images 1566MH0006270010600713C00, 1566MH0006270010600715C00, and 1566MH0006270010600717C00. (b) Rock exposure containing ChemCam targets Waterfall_Bridge and Duck_Brook_Bridge, acquired by Mastcam-34 on Sol 1682 (sequence mcam08745). 

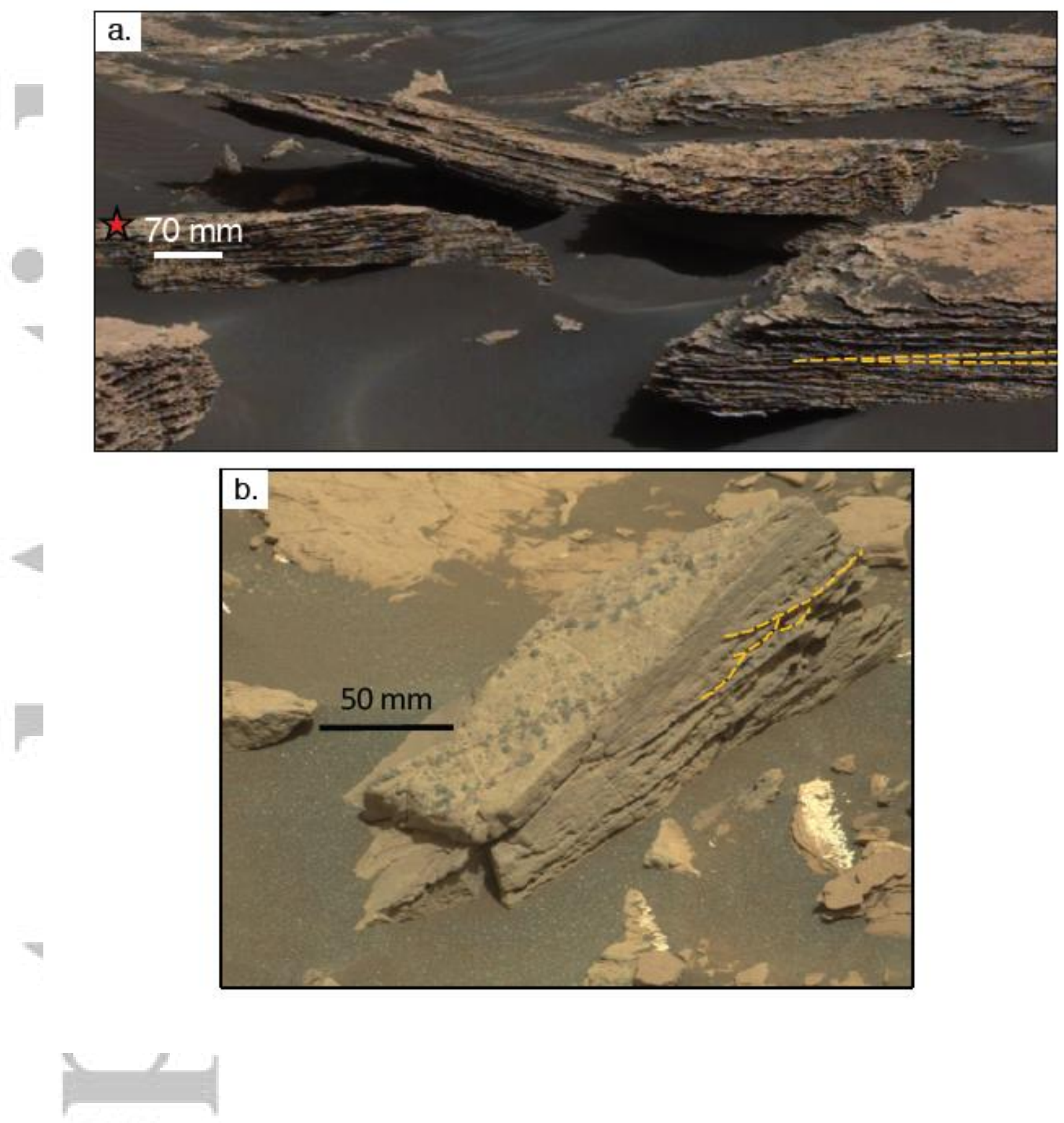

Figure 7. Examples of cross-stratified sandstones at Newport Ledge (a) and Heron Island (b), confirming the presence of sand in the rocks. (a) Rock exposure with the ChemCam LIBS target Mount_Gilboa, marked by a red star acquired by Mastcam-34 on Sol 1691 (sequence mcam08806). The dashed orange lines highlight low-angle cross-bedding. (b) A rock about a meter away from the ChemCam LIBS target, Heron_Island, acquired by Mastcam-100 on Sol 1714 (sequence mcam08947) showing trough cross-bedding, marked by the dashed orange lines. 